\title{
Article \\ A Thermally Conductive Pt/AAO Catalyst for Hydrogen Passive Autocatalytic Recombination
}

\author{
Alina E. Kozhukhova, Stephanus P. du Preez *, Aleksander A. Malakhov and Dmitri G. Bessarabov *ID \\ Hydrogen South Africa (HySA) Infrastructure, Faculty of Engineering, North-West University (NWU), \\ Potchefstroom Campus, Private Bag X6001, Potchefstroom 2520, South Africa; 31532187@nwu.ac.za (A.E.K.); \\ 31541356@nwu.ac.za (A.A.M.) \\ * Correspondence: Faan.duPreez@nwu.ac.za (S.P.d.P.); Dmitri.Bessarabov@nwu.ac.za (D.G.B.)
}

Citation: Kozhukhova, A.E.; du Preez, S.P.; Malakhov, A.A.; Bessarabov, D.G. A Thermally Conductive Pt/AAO Catalyst for Hydrogen Passive Autocatalytic Recombination. Catalysts 2021, 11, 491. https://doi.org/10.3390/ catal11040491

Academic Editor: Stefano Cimino

Received: 8 March 2021

Accepted: 24 March 2021

Published: 12 April 2021

Publisher's Note: MDPI stays neutral with regard to jurisdictional claims in published maps and institutional affiliations.

Copyright: (c) 2021 by the authors. Licensee MDPI, Basel, Switzerland. This article is an open access article distributed under the terms and conditions of the Creative Commons Attribution (CC BY) license (https:/ / creativecommons.org/licenses/by/ $4.0 /)$.
Abstract: In this study, a Pt/anodized aluminum oxide (AAO) catalyst was prepared by the anodization of an $\mathrm{Al}$ alloy (Al6082, 97.5\% Al), followed by the incorporation of Pt via an incipient wet impregnation method. Then, the Pt/AAO catalyst was evaluated for autocatalytic hydrogen recombination. The Pt/AAO catalyst's morphological characteristics were determined by scanning electron microscopy (SEM) and transmission electron microscopy (TEM). The average Pt particle size was determined to be $3.0 \pm 0.6 \mathrm{~nm}$. This Pt/AAO catalyst was tested for the combustion of lean hydrogen ( $0.5-4 \mathrm{vol} \% \mathrm{H}_{2}$ in the air) in a recombiner section testing station. The thermal distribution throughout the catalytic surface was investigated at $3 \mathrm{vol} \%$ hydrogen $\left(\mathrm{H}_{2}\right)$ using an infrared camera. The Al/AAO system had a high thermal conductivity, which prevents the formation of hotspots (areas where localized surface temperature is higher than an average temperature across the entire catalyst surface). In turn, the Pt stability was enhanced during catalytic hydrogen combustion (CHC). A temperature gradient over $70 \mathrm{~mm}$ of the $\mathrm{Pt} / \mathrm{AAO}$ catalyst was $23^{\circ} \mathrm{C}$ and $42{ }^{\circ} \mathrm{C}$ for catalysts with uniform and nonuniform (worst-case scenario) Pt distributions. The commercial computational fluid dynamics (CFD) code STAR-CCM+ was used to compare the experimentally observed and numerically simulated thermal distribution of the Pt/AAO catalyst. The effect of the initial $\mathrm{H}_{2}$ volume fraction on the combustion temperature and conversion of $\mathrm{H}_{2}$ was investigated. The activation energy for $\mathrm{CHC}$ on the $\mathrm{Pt} / \mathrm{AAO}$ catalyst was $19.2 \mathrm{~kJ} / \mathrm{mol}$. Prolonged $\mathrm{CHC}$ was performed to assess the durability (reactive metal stability and catalytic activity) of the Pt/AAO catalyst. A stable combustion temperature of $162.8 \pm 8.0^{\circ} \mathrm{C}$ was maintained over $530 \mathrm{~h}$ of $\mathrm{CHC}$. To confirm that Pt aggregation was avoided, the Pt particle size and distribution were determined by TEM before and after prolonged $\mathrm{CHC}$.

Keywords: anodized aluminum; Al6082; passive autocatalytic recombiner; catalytic hydrogen combustion

\section{Introduction}

In nuclear power plants (NPPs) and the mining industry, passive autocatalytic recombiners (PARs) are considered hydrogen $\left(\mathrm{H}_{2}\right)$ control systems for emergency gas removal based on their recombination with ambient oxygen. It is widely recognized that, in underground mines, the replacement of diesel-powered vehicles with $\mathrm{H}_{2}$-fueled trucks will result in a cleaner environment for underground mineworkers. Water is the only byproduct of $\mathrm{H}_{2}$ combustion/oxidation, instead of the otherwise harmful greenhouse gases (e.g., $\mathrm{CO}_{\mathrm{x}}$, $\mathrm{CH}_{4}$ ) and $\mathrm{NO}_{x}$ generated during the combustion of hydrocarbon-based fuels. Furthermore, besides the gaseous exhausts, harmful pollutants and particulate matter form during incomplete combustion of diesel fuel hydrocarbons, which presents underground workers with further harmful exposure.

However, the utilization of $\mathrm{H}_{2}$ in confined spaces is accompanied by the risk of accidental gas release and its accumulation. In NPPs, $\mathrm{H}_{2}$ may be generated unintentionally as a result of the reactor fuel overheating and the chemical reaction of fuel rods' zirconium 
cladding with steam [1]. When the flammable concentration of $\mathrm{H}_{2}$ (4-75 vol\% in the air) accumulates, damage to/loss of structures and equipment and loss of life in mines and NPPs may occur during accidental combustion. Therefore, the issue of safety must be taken into account in the event of accidental $\mathrm{H}_{2}$ release. PARs are considered to play a key role in accident mitigation in mines and NPPs.

A PAR is a safety device based on the idea of catalytic recombination of $\mathrm{H}_{2}$ and $\mathrm{O}_{2}$ according to the reaction:

$$
\mathrm{H}_{2}+0.5 \mathrm{O}_{2} \rightarrow \mathrm{H}_{2} \mathrm{O}, \Delta \mathrm{H}=240 \mathrm{~kJ} / \mathrm{mol}
$$

PARs function without the requirement for an external power source. $\mathrm{H}_{2}$ mitigation occurs spontaneously when the gas mixture reaches the catalyst surface. The air that contains $\mathrm{H}_{2}$ enters at the lower end of a PAR, and exothermic reaction heat is formed as the $\mathrm{H}_{2}$ is recombined. Natural convection forces airflow through the PAR. $\mathrm{H}_{2}$ removal in PARs commences at nonflammable $\mathrm{H}_{2}$ concentrations (1-2 vol\%), thereby preventing the formation of explosive mixtures with the air. However, when a large amount of $\mathrm{H}_{2}$ is released, as in the event of a severe accident, the recombiner can overheat due to the large exothermic effect. Therefore, the PAR itself may then become the $\mathrm{H}_{2}$ ignition source.

The effect of thermal distribution throughout the PAR catalyst section on $\mathrm{H}_{2}$ risk mitigation has been studied mainly by using numerical simulations, specifically, computational fluid dynamics (CFD) [2,3]. Results of studies have shown that the thermal distribution over the catalytic surface plays an important role in risk mitigation related to the PAR autoignition. CFD modeling is widely recognized as a powerful numerical tool to analyze hydrogen safety issues. CFD simulations are generally in good agreement with experimental results and show a high level of predictability [4].

Catalytic hydrogen combustion (CHC) will likely play a key role in a hydrogen economy for safety purposes (in PARs) as well as for heating appliances (cooking and spatial heating). The reaction is relatively safe (no flashback phenomenon and $\mathrm{NO}_{\mathrm{x}}$ emission, under certain conditions) and controllable [5]. Among the platinum group metals, $\mathrm{Pt}$ and $\mathrm{Pd}$ are considered to be the most suitable catalysts for CHC [6-10]. They have also found diverse applications as catalytic materials, such as chemical and biosensing systems [11-13], proton exchange membrane fuel cells [14,15], electrochemical $\mathrm{H}_{2}$ compressors $[16,17]$. When addressing research on $\mathrm{CHC}$, it should be emphasized that the catalyst support significantly affects the activity of the catalytic system as it improves the dispersion of a reactive metal, affects the heat distribution throughout the catalyst surface, and prevents/limits catalyst deactivation (support degradation/reactive metal aggregation). As far as we could determine, catalyst supports, such as ceramics, metal oxides $\mathrm{ZrO}_{2}, \mathrm{TiO}_{2}, \mathrm{SiO}_{2}[6,8,18-21], \gamma-\mathrm{Al}_{2} \mathrm{O}_{3}$ washcoat [22], $\mathrm{SiC}$ foam [23,24], and stainless steel mesh (SSM) [25] have been examined for CHC.

Kramer et al. studied $\mathrm{PdO}_{x}$ and $\mathrm{Pd}$ catalysts supported on a $\gamma-\mathrm{Al}_{2} \mathrm{O}_{3}$ washcoat for $\mathrm{CHC}$. They observed $<40 \% \mathrm{H}_{2}$ conversion at low inlet temperatures $\left(<125^{\circ} \mathrm{C}\right)$. Furthermore, there was an increase in $\mathrm{H}_{2}$ conversion with an increase in the inlet temperature $\left(100 \%\right.$ conversion at $\left.200{ }^{\circ} \mathrm{C}\right)$. Of importance here is that the presence of water vapor caused a reduction in $\mathrm{H}_{2}$ conversion; furthermore, it was found that the lower the inlet temperature, the more significant was the effect of water vapor [22]. These results of Kramer et al. could be expected, as the presence of water accelerates catalyst aggregation, hence reducing the catalytic activity [26]. In a study by Du Preez et al., aggregation of Pt catalyst occurred on the SSM support during $\mathrm{CHC}$ at $420-520^{\circ} \mathrm{C}$. This occurrence was ascribed to the fact that the SSM surface allows significant Pt mobility at high temperatures. However, these authors demonstrated that calcination of the SSM support at $500-1000{ }^{\circ} \mathrm{C}$ resulted in the stabilization of Pt particles, effectively preventing their aggregation during $\mathrm{CHC}$ [25].

Deshpande and Madras compared the use of $\mathrm{ZrO}_{2}$ and $\mathrm{TiO}_{2}$ as supports for $\mathrm{Pt}$ and $\mathrm{Pd}$ catalysts for CHC. The activity of the $\mathrm{Pt}$ and $\mathrm{Pd}$ catalysts was found to be higher with $\mathrm{TiO}_{2}$ support than with $\mathrm{ZrO}_{2}$; complete conversions of $\mathrm{H}_{2}$ over $\mathrm{TiO}_{2}$ supported catalysts were obtained at a temperature of $100{ }^{\circ} \mathrm{C}$ [20]. Hanson and Boudart studied the reaction between 
$\mathrm{H}_{2}$ and $\mathrm{O}_{2}$ over $\mathrm{Pt} / \mathrm{SiO}_{2}$ catalyst in excess $\mathrm{H}_{2}$ and excess $\mathrm{O}_{2}$. The catalyst with smaller Pt particles (higher catalyst dispersion) exhibited higher catalytic activity in excess $\mathrm{H}_{2}$; the catalytic activity was almost independent of Pt particle size in excess $\mathrm{O}_{2}$ [21]. They then proposed that the latter observation can be related to the passivation/deactivation of the catalytic surface in excess of $\mathrm{O}_{2}$, especially in the case of smaller Pt particles. It was noticed that smaller Pt particles had higher $\mathrm{O}_{2}$ adsorption capacity, which resulted in the formation of Pt oxide. In turn, the presence of Pt oxide decreased the $\mathrm{H}_{2}$ combustion reactivity.

The use of $\mathrm{SiC}$ as catalyst support for $\mathrm{CHC}$ has been reported $[23,24]$. In a study by Fernández et al., the $\mathrm{SiC}$ support was found to be an appropriate material for the design of heating devices due to its high thermal conductivity [23]. The ability of catalyst support to dissipate/distribute heat is of critical importance when a catalytic system is employed for heating purposes. For example, the formation of hotspots (areas where localized surface temperature is higher than an average temperature across the entire catalyst surface) can be avoided if the catalyst support provides a uniform temperature distribution throughout the catalytic surface. Schefer et al. found that the presence of hotspots can result in $\mathrm{H}_{2}$ ignition if its autoignition temperature is exceeded [27]. Fumey et al. employed $\mathrm{SiC}$ foam with $\mathrm{Pt}$ coating as a catalyst for a catalytic burner, suitable for domestic cooking use. They found a uniform catalytic reaction of $\mathrm{H}_{2}$ combustion with a burner surface temperature $<715^{\circ} \mathrm{C}$ at an $\mathrm{H}_{2}$ flow rate of 5-15 Nl/min. The burner could achieve temperatures exceeding that of the $\mathrm{H}_{2}$ ignition temperature $\left(>585{ }^{\circ} \mathrm{C}\right)$ due to specialized burner design. The layered structure and alternation of $\mathrm{SiC}$ foam discs (diffuser and catalytic disks) allowed the controlled $\mathrm{H}_{2}$ ignition in an air atmosphere between disks, allowing burner surface temperatures $>585{ }^{\circ} \mathrm{C}[24]$.

In a recent study, in their preliminary investigations, Kozhukhova et al. found the $\mathrm{Al} / \mathrm{AAO}$ support to be suitable as catalyst support for $\mathrm{CHC}$ purposes. The $\mathrm{Pt} / \mathrm{AAO}$ catalyst was found to be highly stable over a prolonged $\mathrm{CHC}$ reaction time of $530 \mathrm{~h}$. The stabilization of $\mathrm{Pt}$ particles was achieved, possibly due to the high thermal conductivity of the $\mathrm{Al} / \mathrm{AAO}$ system. The heat produced during $\mathrm{CHC}$ was displaced from the $\mathrm{AAO}$ to the $\mathrm{Al}$ core, and a mild average catalyst surface temperature was achieved, which most likely limited Pt aggregation [28].

In the present work, we now demonstrate the use of $\mathrm{Pt} / \mathrm{AAO}$ as a catalyst in an inhouse-developed recombiner section testing station. The design of the testing station allows for the characterization of the thermal distribution of the catalyst section under conditions similar to those in real-world PAR applications [2]. The Pt/AAO catalyst performance was determined for $\mathrm{CHC}$ using lean $\mathrm{H}_{2}$ mixtures $\left(0.5-4 \mathrm{vol} \% \mathrm{H}_{2}\right)$. The utilization of the $\mathrm{Pt} / \mathrm{AAO}$ catalyst for PAR application is a prospective solution for low thermal conductive catalysts currently used in commercial PARs. Moreover, cheap Al alloy used as a substrate material for catalyst support preparation affords significant cost savings when compared to ceramic support materials. Therefore, the catalyst cost reduction along with the increase in its performance may afford a widespread penetration of PAR technology.

The temperature distribution across the catalytic surface during $\mathrm{CHC}$ was determined using an infrared (IR) camera. Structural and chemical characteristics of the catalyst and catalyst support were determined using scanning electron microscopy (SEM) and transmission electron microscopy (TEM). A numerical model was created in STAR-CCM+ in combination with the chemistry tools of CHEMKIN to investigate temperature distribution throughout the Pt/AAO catalyst and to compare it with the experimental data [29].

\section{Results and Discussion}

\subsection{Catalytic Test in the Recombiner Section Testing Station}

Preliminary work by Kozhukhova et al. showed the potential of an AAO as suitable catalyst support for $\mathrm{CHC}$ purposes [28]. The high thermal conductivity of an Al/AAO system afforded a mild average surface temperature throughout the catalyst surface that likely prevented catalyst deactivation during $\mathrm{CHC}$. Moreover, due to the AAO's structural features (hexagonally organized array of pores) and the high dispersion of the reactive 
metal (Pt), catalysts with high catalytic activity are obtained. In addition, the Al6082 alloy used in the present study is inexpensive and can be machined to any shape before the anodization, affording such a catalyst with a wide variety of practical applications. Therefore, the use of AAO as catalyst support affords not only significant cost savings (compared to the expensive ceramic catalyst support currently used in commercial PARs) but provides high catalytic activity and stability that that extends the operation time of such a catalytic system.

The AAO morphology, and Pt particle size and morphology, were determined before $\mathrm{CHC}$ procedures. Figure 1 shows representative bright-field and high-resolution TEM (HRTEM) images of the Pt/AAO catalyst.

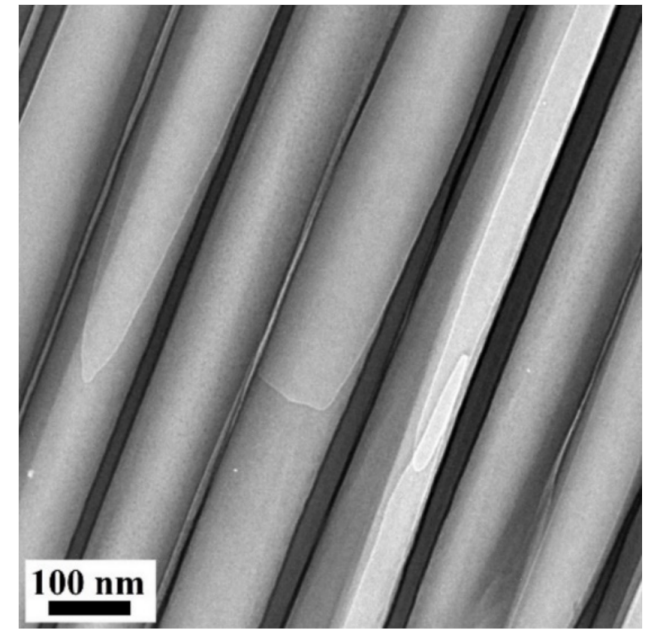

(a)

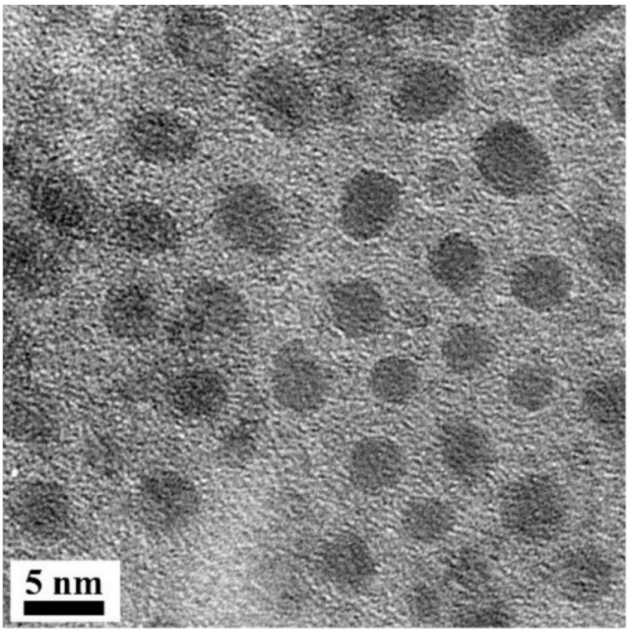

(b)

Figure 1. Pt/AAO catalyst before catalytic hydrogen combustion ( $\mathrm{CHC}$ ): (a) TEM bright-field image of cross-sectioned AAO pore channels; (b) HRTEM image of interpore-channel Pt particles.

Figure 1a shows the nanopore walls and channels of the Pt/AAO catalyst and suggests that the pores were tubular and relatively well constructed. Figure $1 \mathrm{~b}$ shows that Pt particles are present within the AAO channels. Particle size measurements were carried out over several TEM images taken of different areas of a FIB lamella. The average diameter of $\mathrm{Pt}$ particles for the $\mathrm{Pt} / \mathrm{AAO}$ catalyst was $3.0 \pm 0.6 \mathrm{~nm}$.

$\mathrm{CHC}$ over the prepared $\mathrm{Pt} / \mathrm{AAO}$ catalyst was studied in the recombiner section testing station at a $3 \mathrm{vol} \% \mathrm{H}_{2}$ concentration, at a gas mixture flow velocity of $9.5 \mathrm{~m} / \mathrm{s}$. Five $\mathrm{Pt} / \mathrm{AAO}$ catalysts (prepared similarly) were placed inside the testing station constituting the catalyst section. During $\mathrm{CHC}$ procedures, thermal measurements of each catalyst were recorded every $1 \mathrm{~s}$. The CHC tests were repeated in triplicate, and the standard deviation was calculated for each catalyst. There was a period of seven days between each repetition. During these aging periods between tests, catalysts were kept in the ambient atmosphere to investigate the behavior of the catalyst under conditions comparable to real-world PARs. The aging procedure was assumed to have a detrimental effect on the catalyst due to passivation by $\mathrm{O}_{2}$ and fouling. Poisoning by oxidants may cause changes in the oxidation state of the active catalyst and, hence, decrease the catalytic activity of the catalyst [26]. Hanson and Boudart observed that the passivation of Pt catalysts in excess $\mathrm{O}_{2}$ at low temperatures $\left(0-100{ }^{\circ} \mathrm{C}\right)$ resulted in a loss in catalytic activity [21]. Ostermaier et al. reported the deactivation of a Pt/ $\mathrm{Al}_{2} \mathrm{O}_{3}$ catalyst due to the formation of $\mathrm{Pt}$ oxide in an $\mathrm{O}_{2}$ atmosphere [30]. The deactivation of the catalyst was studied at temperatures of $95-200{ }^{\circ} \mathrm{C}$. Deactivation was found to have a greater effect at low temperatures on catalysts with smaller Pt particles. Another important issue to consider is the inevitable dry deposition of fine solid material (dust) from the ambient atmosphere onto the catalysts used in PAR devices. This occurrence is referred to as fouling and prevents $\mathrm{H}_{2}$ from accessing the 
reactive sites of a catalyst [26]. Figure 2 shows average combustion temperature profiles for five catalysts for $1 \mathrm{~h}$ of $\mathrm{CHC}$.

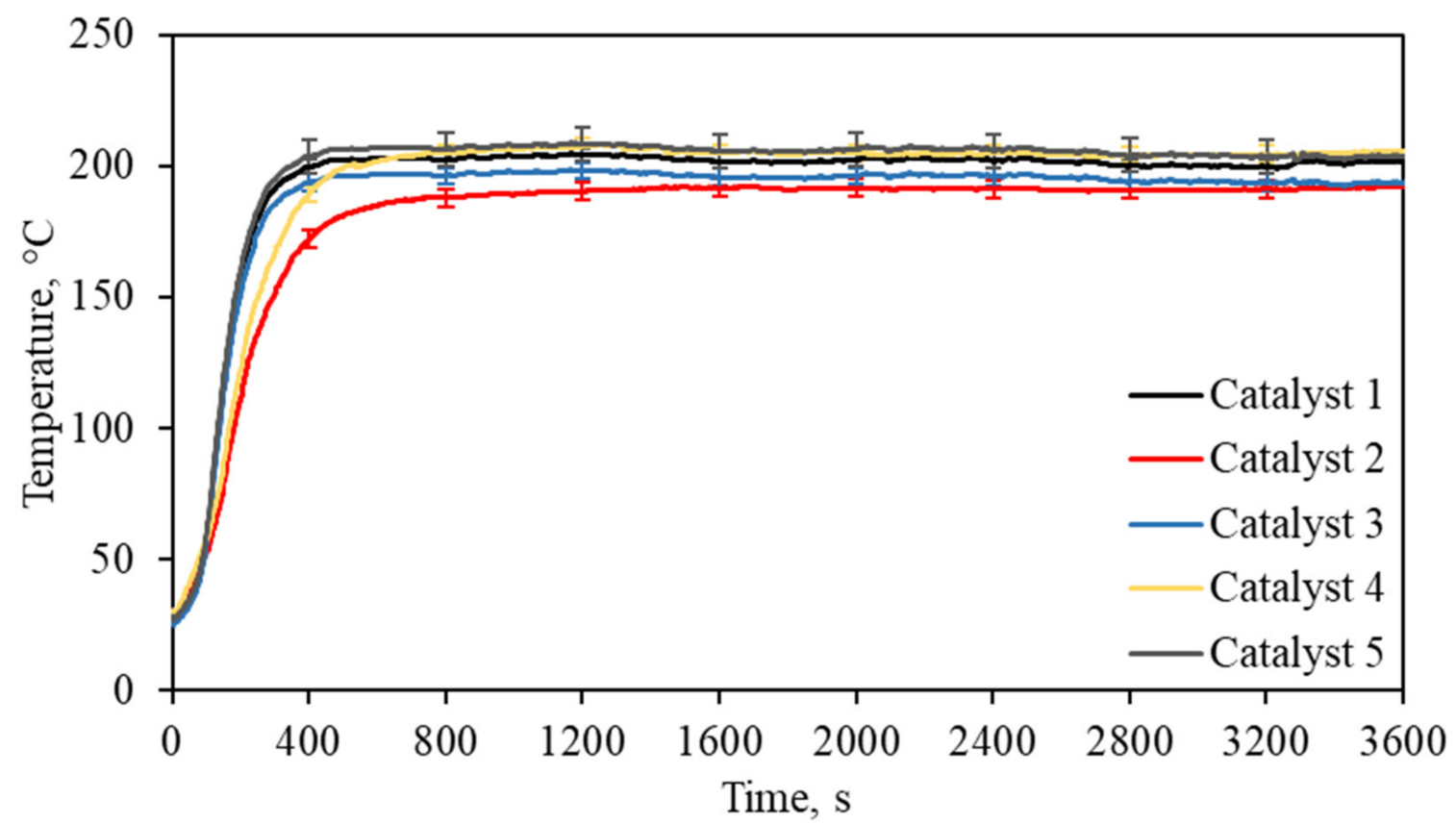

Figure 2. Combustion temperature profiles of $\mathrm{Pt} / \mathrm{AAO}$ catalysts for $1 \mathrm{~h}$ of combustion at $3 \% \mathrm{H}_{2}$ volume fraction in air.

Figure 2 shows a steady increase in catalyst temperature for each catalyst during the first $400 \mathrm{~s}$ of $\mathrm{CHC}$. Here, $\mathrm{CHC}$ was initiated spontaneously at room temperature $\left(26-28^{\circ} \mathrm{C}\right)$. The average combustion temperature was calculated for each catalyst based on three repeats. Stable combustion temperatures of $201.5 \pm 2.6,191.0 \pm 3.3,195.3 \pm 3.3$, $205.1 \pm 3.1$, and $204.9 \pm 6.5^{\circ} \mathrm{C}$ were reached for the catalysts $1-5$, respectively. Considering that a relatively consistent average combustion temperature was achieved for each catalyst per test and that the $\mathrm{CHC}$ reaction initiated spontaneously suggests that the catalysts maintained their catalytic activity. The latter observations may be ascribed to the fact that the AAO support promotes the stabilization of $\mathrm{Pt}$ particles at the temperatures, as shown in Figure 2 [28]. Furthermore, the spontaneity of the reaction suggests that the catalyst preparation method yielded samples with relatively similar $\mathrm{CHC}$ reaction kinetics. It is also interesting to note the detrimental effects of catalyst exposure to ambient conditions during the periods between the tests (i.e., deactivation by ambient oxygen). An important perspective is to also determine the effect of prolonged exposure to air (several months) on the catalytic activity of $\mathrm{Pt} / \mathrm{AAO}$ catalysts.

To characterize the Pt/AAO catalyst from a kinetic point of view, a series of experiments were carried out at the initial volume fraction of $\mathrm{H}_{2}$ in air ranging from 0.5 to $4.0 \mathrm{vol} \%(0.132-1.031 \mathrm{mmol} / \mathrm{s}$, respectively). The conversion and combustion temperature were measured at an inlet flow velocity of $9.5 \mathrm{~m} / \mathrm{s} \mathrm{H}_{2}$ /air. Close to $100 \% \mathrm{H}_{2}$ conversions were observed for the initial $\mathrm{H}_{2}$ volume fractions of $>4 \mathrm{vol} \%$. $\left(\mathrm{H}_{2}\right.$ volume fractions of $>4$ vol\% were, therefore, not considered here.) Figure 3 shows the differences between the catalyst temperature before exposure to $\mathrm{H}_{2}$ /air mixture $\left(\mathrm{T}_{\text {initial }}\right)$ and after achieving steady-state conditions (T) (primary y-axis). The conversion of $\mathrm{H}_{2}$ at the various initial molar fractions of $\mathrm{H}_{2}$ is shown on the secondary y-axis. The initial temperatures of the catalyst were in the range $29-30{ }^{\circ} \mathrm{C}$. For simpler comprehension of further results, the temperature and initial concentration of $\mathrm{H}_{2}$ are presented in Arrhenius equation units. 


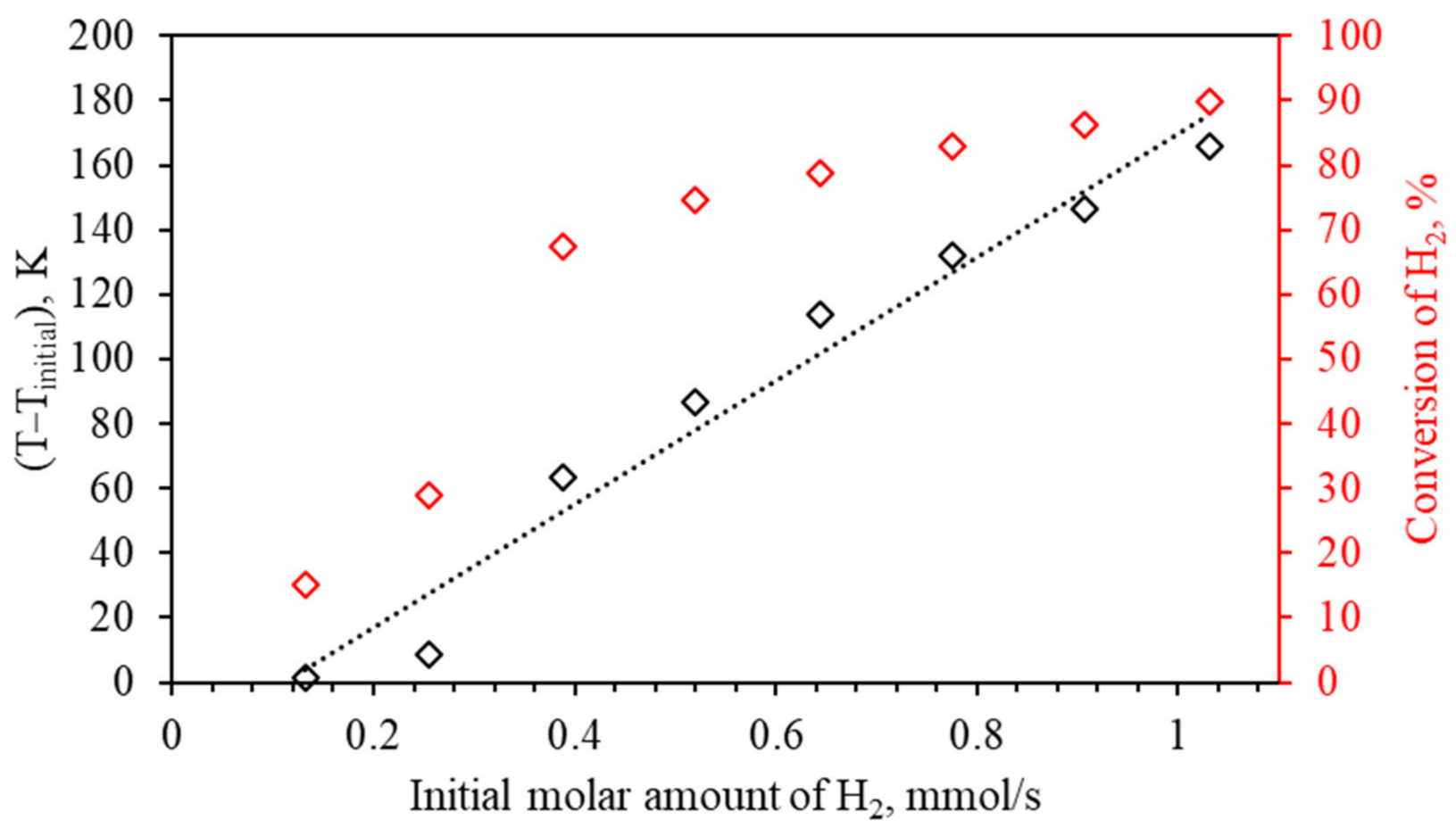

Figure 3. Catalyst surface temperature differences between initial temperature and temperature at steady-state conditions ( $\mathrm{T}-\mathrm{T}_{\text {initial }}$, primary y-axis) and conversion of $\mathrm{H}_{2}$ (secondary y-axis) as a function of the initial molar amount of $\mathrm{H}_{2}$ in air.

As is evident in Figure 3, the temperature of the catalyst at steady-state increased linearly with an increase in the initial molar amount of $\mathrm{H}_{2}$, which is in agreement with the results obtained by Nguyen et al. [31]. Figure 3 further shows that the conversion of $\mathrm{H}_{2}$ is dependent on the initial amount of $\mathrm{H}_{2}$. The $\mathrm{H}_{2}$ conversion increased from $15 \%$ to $90 \%$, with an increase in the initial amount of $\mathrm{H}_{2}$. The maximum $\mathrm{H}_{2}$ conversion of $90 \%$ was obtained at the highest initial molar amount of $\mathrm{H}_{2}$ in air. The data obtained was used to determine the activation energy $\left(\mathrm{E}_{\mathrm{a}}\right)$ of $\mathrm{CHC}$ on the Pt/AAO catalyst.

Due to the high exothermicity of the $\mathrm{CHC}$ reaction, the performance of the experiment under isothermal conditions is problematic and inconvenient. Therefore, in this work, the data obtained under adiabatic conditions were used to determine the reaction kinetics of the $\mathrm{CHC}$ reaction. According to Nguyen et al., the transformation of adiabatic data to isothermal is possible [31]. Figure 4a shows the change in the relative $\mathrm{H}_{2}$ fraction overtime during $\mathrm{CHC}$ at constant temperatures. The Arrhenius plot is shown in Figure $4 \mathrm{~b}$.

Figure 4 a shows that the relative fraction of $\mathrm{H}_{2}$ dependence as a function of time gives an exponential function at different constant temperatures (except in the case of $311 \mathrm{~K}$ ), thus corresponding to a first-order reaction. The latter observation corresponds with those made by Nguyen et al. [21,31] and Hanson and Boudart [21,31]. The rate constant can then be calculated as follows [31]:

$$
\begin{gathered}
\ln \left(\chi_{\mathrm{H} 2,0}\right)-\ln \left(\chi_{\mathrm{H} 2}\right)=\mathrm{k} \tau \\
\mathrm{k}=\left(\ln \left(\chi_{\mathrm{H} 2,0}\right)-\ln \left(\chi_{\mathrm{H} 2}\right)\right) / \tau
\end{gathered}
$$

where $\tau$ is the time required to reach a stable combustion temperature, $\chi_{\mathrm{H} 2,0}$ and $\chi_{\mathrm{H} 2}$ are the $\mathrm{H}_{2}$ compositions at $\tau=0$ and time required to reach steady-state conditions $(\tau)$, respectively. 


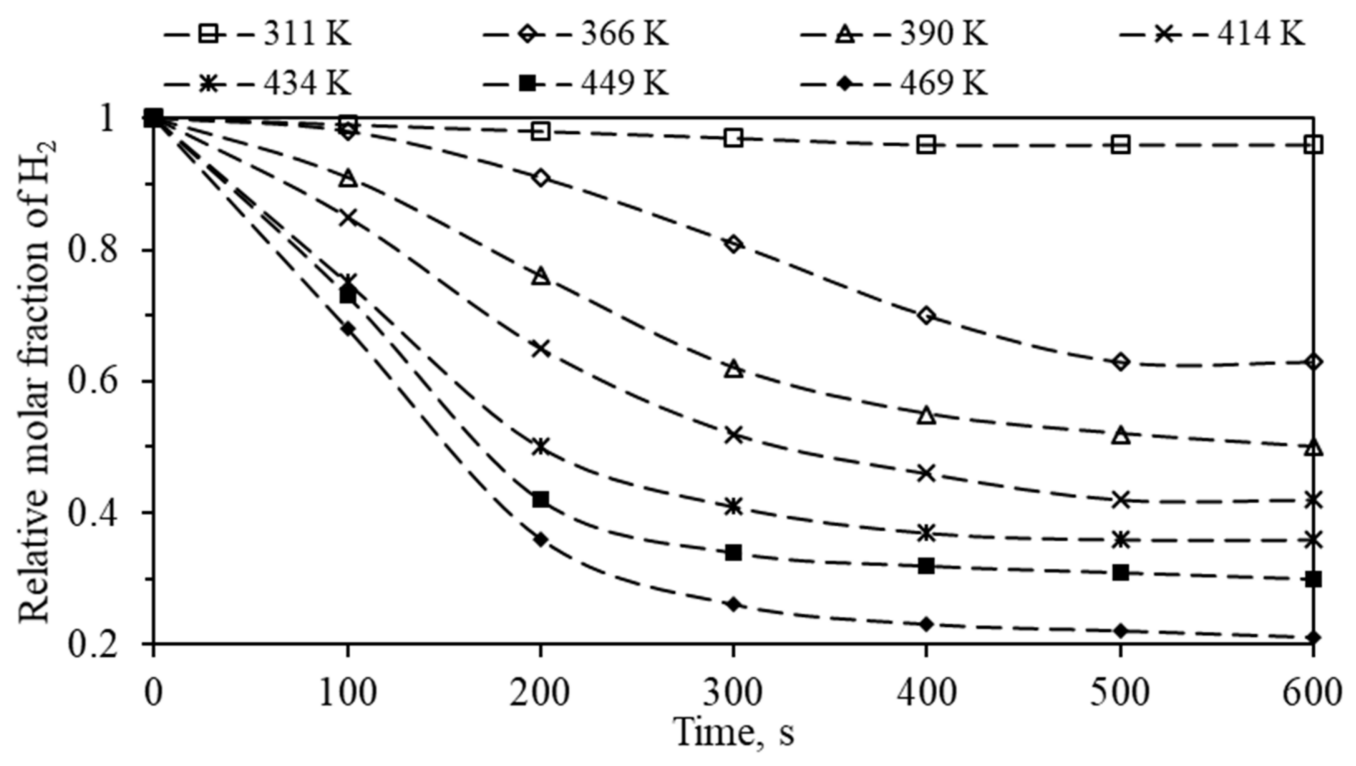

(a)

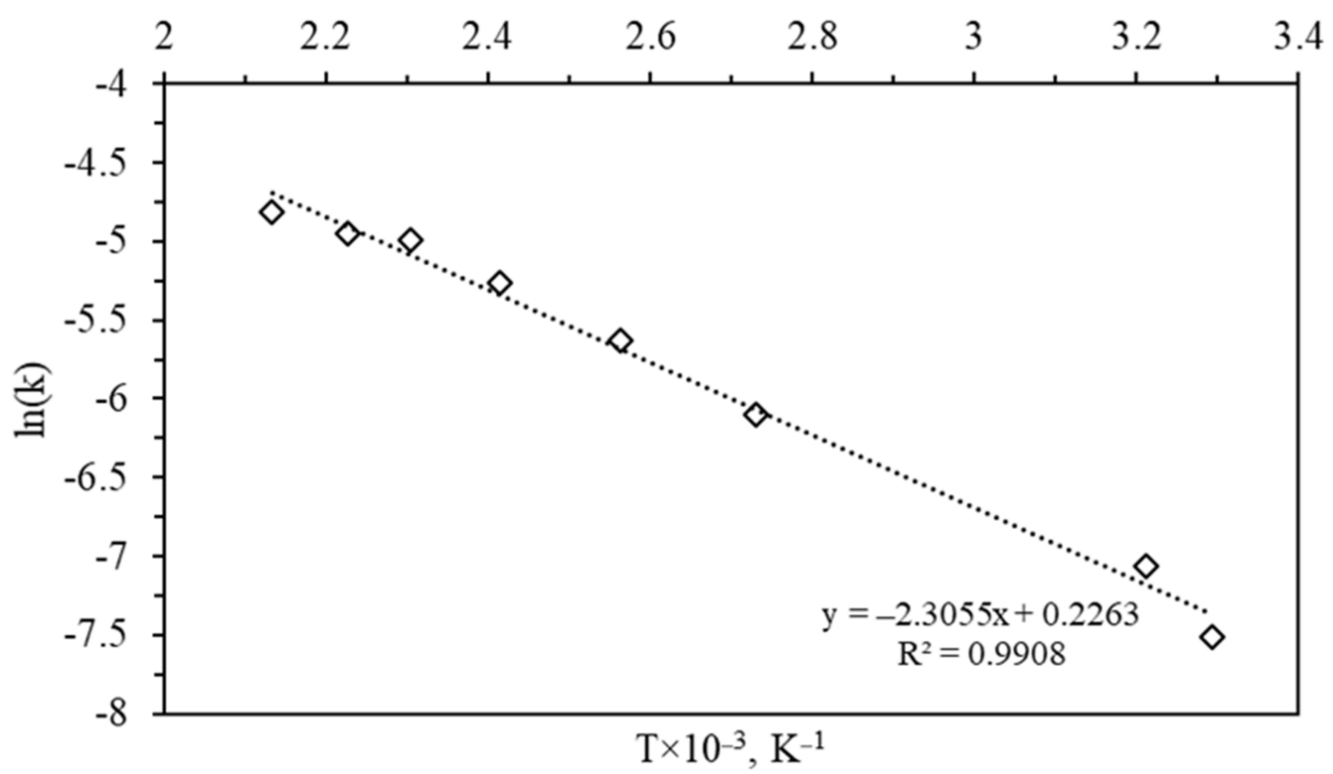

(b)

Figure 4. (a) Relative molar fractions of $\mathrm{H}_{2}$ as a function of time at constant temperatures under steady-state conditions; (b) Arrhenius plot for $\mathrm{CHC}$ on the Pt/AAO catalyst.

Figure $4 \mathrm{~b}$ shows that the temperature dependence of the reaction rate represents a linear function. The $E_{a}$ calculated from the data presented in Figure $4 \mathrm{~b}$ is $19.2 \mathrm{~kJ} / \mathrm{mol}$. A similar $\mathrm{E}_{\mathrm{a}}$ value of $22.3 \mathrm{~kJ} / \mathrm{mol}$ for $\mathrm{CHC}$ on a Pt/AAO catalyst has been reported by Joshi et al. [32]. However, the $\mathrm{E}_{\mathrm{a}}$ value of various catalytic systems used for $\mathrm{CHC}$ can range from 7 to $46 \mathrm{~kJ} / \mathrm{mol}$. For instance, a $\mathrm{Co}_{3} \mathrm{O}_{4} / \mathrm{Cr}_{2} \mathrm{O}_{3}$ catalyst has an $\mathrm{E}_{\mathrm{a}}$ of $10.3 \mathrm{~kJ} / \mathrm{mol}$ [33], whereas a Pt/washcoat catalyst has an $\mathrm{E}_{\mathrm{a}}$ of $8.7 \mathrm{~kJ} / \mathrm{mol}$ [34]. For $\mathrm{CHC}$ using a $\mathrm{Pt} / \mathrm{SiO}_{2}$ catalyst, Hansen and Boudart reported an $\mathrm{E}_{\mathrm{a}}$ of $7.5 \mathrm{~kJ} / \mathrm{mol}$ and $46 \mathrm{~kJ} / \mathrm{mol}$ in excess of $\mathrm{O}_{2}$ and $\mathrm{H}_{2}$, respectively [21]. Meanwhile, Fernández et al. reported an $\mathrm{E}_{\mathrm{a}}$ of $35 \mathrm{~kJ} / \mathrm{mol}$ for a Pt $/ \mathrm{SiC}$ catalyst with an excess of $\mathrm{O}_{2}$ [23]. Joshi et al. studied catalytic kinetics of the oxidation of a lean $\mathrm{H}_{2}$ /air mixture on a Pt/ $\mathrm{Al}_{2} \mathrm{O}_{3}$ washcoat monolith catalyst at low temperatures $\left(<90{ }^{\circ} \mathrm{C}\right)$ and determined the effect of aging space velocity and temperature [32]. They reported an $\mathrm{E}_{\mathrm{a}}$ of $45 \mathrm{~kJ} / \mathrm{mol}$ for the freshly prepared catalyst and $22.3 \mathrm{~kJ} / \mathrm{mol}$ for a catalyst 
aged at $800{ }^{\circ} \mathrm{C}$ for $1.5 \mathrm{~h}$. In summary, the $\mathrm{E}_{\mathrm{a}}$ of a specific catalyst for $\mathrm{CHC}$ is strongly dependent on the catalyst support, reactive metal loading, and experimental conditions. The $E_{a}$ value reported here coincides with values reported in the literature.

\subsection{Effect of the Support Structure on Catalyst Performance}

It is generally accepted that the structure of the AAO support has an appreciable effect on the catalytic performance of a Pt/AAO catalyst. AAO formed on a high purity Al substrate can represent an ideal hexagonally organized structure reminiscent of a honeycomb assembly. Due to regularly organized pore distribution and parallel pore channel arrangement, the AAO support offers advantages for high catalyst dispersion, heat, and mass transfer $[35,36]$. When lower purity $\mathrm{Al}$ is used as a substrate for the catalyst support, the formation of the AAO layer with ordered pore arrangement is confounded by the presence of impurities. Impurities cause nonuniform localized electric field flow at the AAO/electrolyte boundary during anodization due to differences in resistivity [30,37,38]. As a result, pits and hillocks, branched pores, nanowires, and other imperfections are formed on and within the AAO layer. The presence of AAO layer imperfections may adversely affect the catalytic activity of an AAO supported catalyst, decreasing the active surface area and the reactive metal dispersion and particle size distribution.

To investigate the effect of the AAO support structure on the catalytic performance in $\mathrm{CHC}$, the $\mathrm{Al}$ substrate was exposed to a $4 \mathrm{~h}$ anodizing procedure. This anodization time of $4 \mathrm{~h}$ was chosen to intentionally form nanowires on the Al surface [30]. Figure 5 shows representative SEM micrographs of the AAO samples prepared by $1 \mathrm{~h}$ and $4 \mathrm{~h}$ anodization.

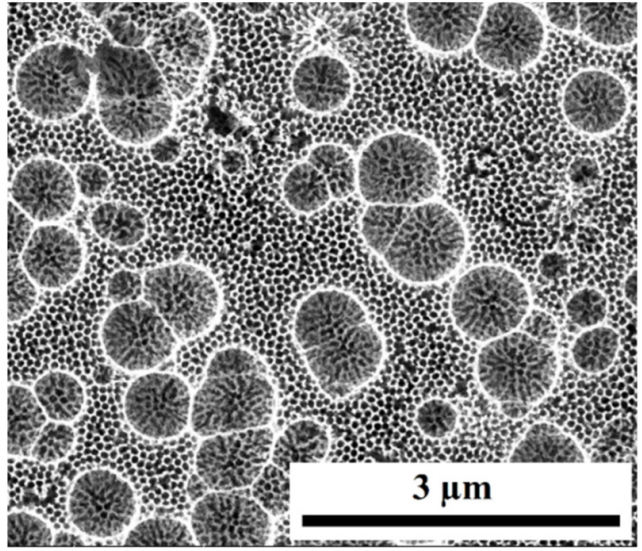

(a)

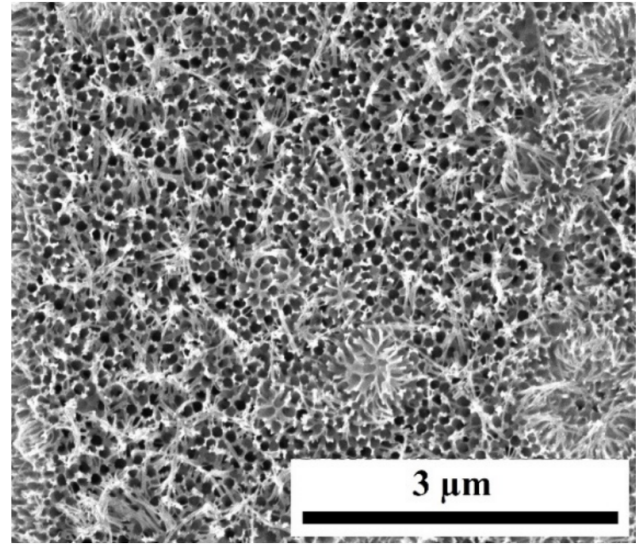

(b)

Figure 5. SEM micrographs of AAO samples prepared by $1 \mathrm{~h} \mathrm{(a)} \mathrm{and} 4 \mathrm{~h}(\mathbf{b})$ anodization.

Figure 5a shows that the $1 \mathrm{~h}$ AAO layer had a relatively ordered pore distribution, but pits were present. The $4 \mathrm{~h}$ AAO layer presented in Figure 5b underwent extensive AAO dissolution during prolonged anodization, and nanowires formed throughout the AAO layer surface. Although the AAO layer presented in Figure 5b did not maintain the hexagonal structural integrity, nanowires are assumed to increase the active surface area after catalyst deposition due to the large exposed surface area. The morphological characteristics of the samples were determined over several SEM images using ImageJ software (National Institutes of Health (NIH), Bethesda, MD, USA). Results are presented in Table 1. The $D_{p}$ and $D_{c}$ were determined manually, and the areas where the pits (Figure 5a) and nanowires (Figure 5b) occurred were excluded from the calculations of the average values. 
Table 1. Morphological characteristics $\left(\mathrm{D}_{\mathrm{p}}, \mathrm{D}_{\mathrm{c}}, n\right.$, and $\left.P\right)$ of AAO samples.

\begin{tabular}{ccccc}
\hline Time of Second Anodization Step $(\mathbf{h})$ & $\mathbf{D}_{\mathbf{p}}(\mathbf{n m})$ & $\mathbf{D}_{\mathbf{c}}(\mathbf{n m})$ & $\boldsymbol{n}$ (pores/ $\left.\boldsymbol{\mu m}^{\mathbf{2}}\right)$ & $\boldsymbol{P}$ \\
\hline 1 & $55.7 \pm 5.7$ & $79.5 \pm 11.0$ & 193 & 48 \\
4 & $86.9 \pm 9.5$ & $121.0 \pm 18.8$ & 85 & 52 \\
\hline
\end{tabular}

$\mathrm{D}_{\mathrm{p}}$ - diameter of pores. $\mathrm{D}_{\mathrm{c}}$-interpore distance. $n$ —pore density. $P$-porosity.

Table 1 shows that the $1 \mathrm{~h}$ AAO sample had a $\mathrm{D}_{\mathrm{p}}$ of $55.7 \mathrm{~nm}$ compared to a $\mathrm{D}_{\mathrm{p}}$ of 86.9 for the $4 \mathrm{~h}$ AAO sample. The $\mathrm{D}_{\mathrm{c}}$ of samples increased from $79.5 \mathrm{~nm}$ to $121.0 \mathrm{~nm}$ with increasing anodization time from $1 \mathrm{~h}$ to $4 \mathrm{~h}$. The increase in $\mathrm{D}_{\mathrm{p}}$ and $\mathrm{D}_{\mathrm{C}}$ may be ascribed to AAO layer dissolution during prolonged anodization and extensive acidic exposure of the sample $[28,30,31,39]$. The $n$ value decreased from 193 to 85 pores $/ \mu \mathrm{m}^{2}$ for AAO samples prepared by 1 and $4 \mathrm{~h}$ anodization, respectively. The decrease in $n$ is likely also caused by layer dissolution during anodization. The thinnest pore walls will undergo dissolution until they are completely dissolved, which causes pores to merge. The latter results in an increase in the $D_{p}$ of pores and, consequently, a decrease in the number of pores. Table 1 further shows that $P$ remained relatively unchanged. This could be expected, as $P$ is defined as a ratio of $D_{p}$ to $D_{c}$; both $D_{p}$ and $D_{c}$ increased, at a similar rate, with an increase in the anodization time. Generally, the morphological characteristics of the catalyst support affect the particle size distribution of the supported reactive metal, its dispersion, mass transfer rates, and, in turn, the catalytic activity [21,40]. For instance, Khodakov et al. showed a direct correlation between catalyst support pore size and $\mathrm{Co}_{3} \mathrm{O}_{4}$ particle size and correlation for a wide variety of mesoporous silica supports [40].

$\mathrm{Pt} / \mathrm{AAO}$ samples were prepared using the 1 , and $4 \mathrm{~h}$ anodized supports and their catalytic activities were compared. The catalytic activity tests were performed in the recombiner section testing station at a $3 \mathrm{vol} \% \mathrm{H}_{2}$ concentration in air. The $\mathrm{CHC}$ tests were performed in triplicate, with seven days between each repetition. The average combustion temperature profiles for the $4 \mathrm{~h}$ AAO catalysts are presented in Figure 6. The average combustion temperature of the $1 \mathrm{~h}$ AAO catalysts presented in Figure 2 is included in Figure 6 (red dashed line) and serves as a reference value.

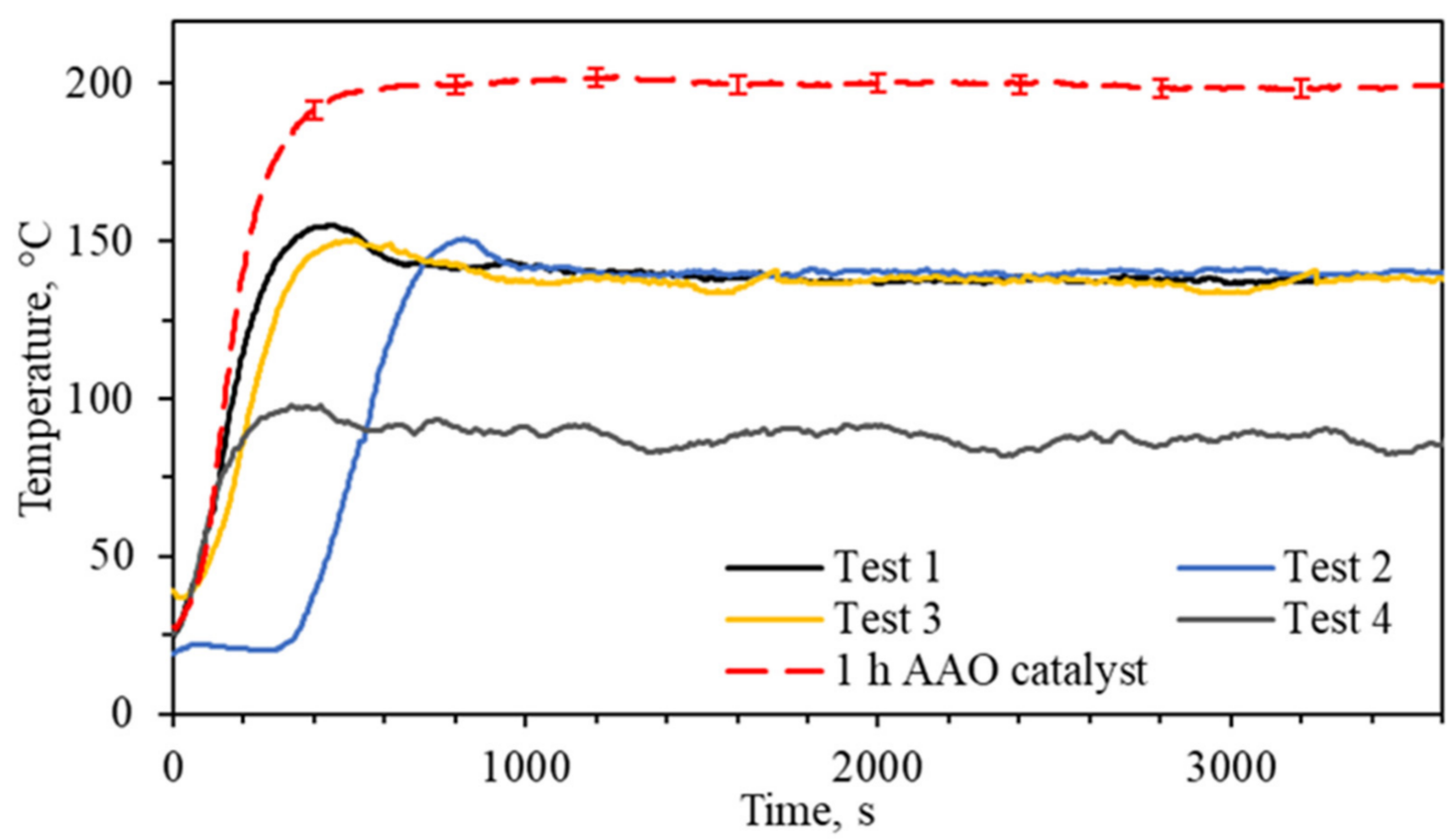

Figure 6. Combustion temperature profiles of $\mathrm{Pt} / \mathrm{AAO}$ catalysts prepared using AAO supports anodized for $1 \mathrm{~h}$ and $4 \mathrm{~h}$ for $1 \mathrm{~h}$ of $\mathrm{CHC}$. 
Figure 6 shows an average combustion temperature of $199.6 \pm 2.9^{\circ} \mathrm{C}$ for the $1 \mathrm{~h}$ AAO catalysts. A stable combustion temperature was reached after $300 \mathrm{~s}$ of $\mathrm{H}_{2}$ exposure. Figure 6 also shows combustion temperature profiles for the $4 \mathrm{~h}$ AAO catalyst. The latter catalyst exhibits very different combustion behavior to the $1 \mathrm{~h}$ AAO catalyst (see Figure 2). During Tests 1 and 2, stable combustion temperatures of $138.9 \pm 1.9$ and $140.1 \pm 0.9{ }^{\circ} \mathrm{C}$

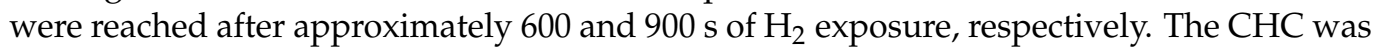
initiated at temperatures of $19-24^{\circ} \mathrm{C}$. The Pt/AAO catalyst had to be preheated to $40{ }^{\circ} \mathrm{C}$ to initiate the $\mathrm{CHC}$ reaction during Test 3 , whereafter a stable combustion temperature of $138.9 \pm 4.0^{\circ} \mathrm{C}$ was reached after $700 \mathrm{~s}$ of $\mathrm{H}_{2}$ exposure.

Considering that the time required for the $\mathrm{CHC}$ reaction to being initiated increased from 600 to $900 \mathrm{~s}$ for Tests 1 and 2, respectively, and that the catalyst had to be preheated during Test 3, this offers a clear indication of catalyst deactivation. The latter is likely caused by Pt aggregation occurring during CHC. As shown in Figure 5b, the surface of the $4 \mathrm{~h}$ AAO contained numerous nanowires; therefore, it is likely that $\mathrm{Pt}$ was deposited onto nanowires, as well as inside the AAO pore channels. It is further likely that the deposition of $\mathrm{Pt}$ on the nanowires might have led to a nonuniform active site distribution, causing differences in heat and mass transfer. In turn, these differences might cause a decrease in catalytic activity. For example, the effect of heat and mass transfer on the catalytic activity of the $\mathrm{Pt} / \gamma-\mathrm{Al}_{2} \mathrm{O}_{3}$ catalyst for $\mathrm{CO}$ oxidation was studied by Arnby et al. [41]. The heat evolved from the exothermic reaction is removed from the active sites to the support material and ambient air; however, heat can accumulate in catalyst particles, causing a constant temperature gradient between the catalyst and the surroundings [41]. Therefore, if the distribution of catalyst particles is nonuniform, the appearance of hotspots is likely. The latter may result in catalyst aggregation, which reduces the catalytic activity of the catalyst. Furthermore, first, the heat transfer limitation in the present study may occur due to an elongated and sophisticated pathway from the surface of the nanowire to the $\mathrm{Al}$ core. Heat present in nanowires may not be transferred as easily and rapidly when compared to the AAO layer directly adhering to the $\mathrm{Al}$ core. Furthermore second, the mass transfer limitation may cause a decline in the reaction rate due to the long diffusion path of the gas phase between the active sites and the catalyst support [41]. Mass transfer limitations locally decrease the concentration of the reactant on the active sites, resulting in a concentration gradient and a decrease in the reaction rate. Figure 6 further shows that although the $\mathrm{CHC}$ initiated spontaneously during Test 4 , the combustion temperature of $88.4 \pm 3.6^{\circ} \mathrm{C}$ was reached after $200 \mathrm{~s}$ of $\mathrm{H}_{2}$ exposure, thus suggesting a further decrease in catalytic activity. The initiation temperature for Test 4 was $25^{\circ} \mathrm{C}$. It is noteworthy that Test 4 initiated spontaneously after the catalyst had to be preheated during Test 3 . However, previous findings indicate that the catalytic activity of a catalyst can be reactivated by increasing its temperature up to $60^{\circ} \mathrm{C}$ [42]. Future work should include the determination of the specific deactivation route.

To compare the efficiency of the 1 and $4 \mathrm{~h}$ AAO catalysts, the conversion of $\mathrm{H}_{2}$ was measured for all $\mathrm{CHC}$ tests. The stable average conversions of $\mathrm{H}_{2}$ during $\mathrm{CHC}$ for $1 \mathrm{~h} \mathrm{AAO}$ catalysts were found to be $96.5 \%, 96.8 \%$, and $98.2 \%$ for all three $\mathrm{CHC}$ tests, respectively. Similar values for percentage conversion might have been expected, as a similar observation was made for the combustion temperatures (Figure 2). The conversion of $\mathrm{H}_{2}$ for the $4 \mathrm{~h}$ AAO catalyst varied over a wide range, which also might have been expected from Figure 6. The stable conversions of $\mathrm{H}_{2}$ were $88.1 \%, 87.9 \%, 88.1 \%$, and $66.9 \%$ for the four $\mathrm{CHC}$ tests, respectively. By plotting the values of combustion temperatures and the corresponding conversions of $\mathrm{H}_{2}$, one may find an obvious correlation between them; the higher the combustion temperature that can be achieved during $\mathrm{CHC}$, the higher the conversion of $\mathrm{H}_{2}$ that may be expected.

From the results in Figure 6 and the values of $\mathrm{H}_{2}$ conversion discussed above, it may be further concluded that the $1 \mathrm{~h}$ AAO catalyst exhibited higher catalytic activity (higher combustion temperatures and $\mathrm{H}_{2}$ conversion) than the $4 \mathrm{~h} \mathrm{AAO}$ catalyst. This is ascribed to the structural differences of the AAO layers formed during the 1 and $4 \mathrm{~h}$ of 
anodization, such as the absence/presence of nanowires (Figure 5). The $4 \mathrm{~h} \mathrm{AAO} \mathrm{layer} \mathrm{is}$ likely susceptible to support collapse due to mechanical, thermal, and chemical stresses induced during the CHC reaction, leading to the loss in catalytic activity [26]. On the other hand, the differences in the catalytic activity of the catalysts may be caused by the different $D_{p}$ values of the AAO layers. As shown in Table 1 , the $D_{p}$ of the $1 \mathrm{~h}$ and $4 \mathrm{~h}$ AAO catalysts were 55.7 and $86.9 \mathrm{~nm}$, respectively. As mentioned above, the greater the $\mathrm{D}_{\mathrm{p}}$ of the support, the larger the catalyst particles that are formed within the support. Therefore, we assumed here that the Pt particles within the $4 \mathrm{~h}$ anodized AAO layer was larger than those within the $1 \mathrm{~h}$ anodized AAO layer. Kozhukhova et al. have obtained Pt nanoparticles with an average diameter of $4.7 \mathrm{~nm}$ for a Pt/AAO catalyst with an AAO D of $59.9 \mathrm{~nm}$, which is in some agreement with the Pt nanoparticle diameter obtained here in the present study for a similar-sized $\mathrm{AAO} \mathrm{D}_{\mathrm{p}}(\mathrm{Pt}$ particles diameter of $3.0 \mathrm{~nm}$ within $\mathrm{AAO}$ with $\mathrm{D}_{\mathrm{p}}$ of $55.7 \mathrm{~nm}$ ) [28]. In both cases, the $\mathrm{Pt} / \mathrm{AAO}$ catalysts have high activity towards $\mathrm{CHC}$ - the reactions initiated spontaneously at room temperature. Khodakov et al. have also investigated the deposition of cobalt $(\mathrm{Co})$ onto silica supports with different $\mathrm{D}_{\mathrm{p}}$ values [40] and found that the Co particle size increased with increasing $D_{p}$; Co particles with an average size of 57-230 A were formed in silica supports with $D_{p}$ of $20-330 \AA$.

Based on the results presented in this section, it is concluded that the structural and morphological characteristics of the AAO layer significantly affect the catalytic activity of the $\mathrm{Pt} / \mathrm{AAO}$ catalyst. Considering that the $1 \mathrm{~h}$ AAO catalyst did not show any evidence of catalytic deactivation, this catalyst was selected for prolonged CHC applications.

\subsection{Catalyst Fatigue Test}

Prolonged CHC was performed to assess Pt/AAO catalyst durability. The $\mathrm{H}_{2}$ content in the exhaust stream was measured after the combustion temperature reached a steady-state value. $\mathrm{A} \mathrm{H}_{2}$ concentration of $<1$ vol\% was determined in the exhaust stream, suggesting near-complete $\mathrm{CHC}$ at the specific flow rate, Pt loading, and catalyst size and orientation. Figure 7 shows the combustion temperature profiles of $\mathrm{Pt} / \mathrm{AAO}$ catalyst during the first $900 \mathrm{~s}$ and for the entire fatigue test $(530 \mathrm{~h})$.

Figure $7 \mathrm{a}$ shows a steady increase in combustion temperature during the first $170 \mathrm{~s}$, which is indicative of the onset of the $\mathrm{CHC}$ reaction. Here, the initiation temperature was $27^{\circ} \mathrm{C}$. After the initial $170 \mathrm{~s}$ of the catalyst fatigue test, the combustion temperature rapidly increased but then stabilized after approximately $550 \mathrm{~s}$ of $\mathrm{H}_{2}$ exposure. The heat generated during $\mathrm{CHC}$ accelerated the reaction rate; therefore, a rapid increase in the combustion temperature was observed after $170 \mathrm{~s}$ of $\mathrm{CHC}$. A temperature of $168.6^{\circ} \mathrm{C}$ was achieved after $550 \mathrm{~s}$ of $\mathrm{CHC}$ reaction. In earlier studies, spontaneous $\mathrm{CHC}$ on $\mathrm{Pt} / \mathrm{SSM}$ and $\mathrm{Pt} / \mathrm{Ti}$ mesh catalysts was found at temperatures $>40$ and $70^{\circ} \mathrm{C}$, respectively $[25,43]$. The higher activity of $\mathrm{Pt} / \mathrm{AAO}$ catalyst (lower initiation temperature) in the present study is related to the smaller Pt particles (3.0 vs. $119.8 \mathrm{~nm}$ for the $\mathrm{Pt} / \mathrm{AAO}$ and $\mathrm{Pt} / \mathrm{SSM}$ catalysts, respectively). Zang et al. showed that CHC proceeded spontaneously on $1 \mathrm{wt} \% \mathrm{Pt} / \mathrm{MgAl}_{2} \mathrm{O}_{4}$ and $\mathrm{Pt} / \mathrm{Ce}_{0.6} \mathrm{Zr}_{0.4} \mathrm{O}_{2} / \mathrm{MgAl}_{2} \mathrm{O}_{4}$ catalysts at initial temperatures as low as $-10{ }^{\circ} \mathrm{C}$ and $\mathrm{H}_{2}$ inlet concentrations of $4 \mathrm{vol} \%$. The authors found that a lower $\mathrm{CHC}$ initiation temperature could be expected with higher $\mathrm{H}_{2}$ inlet concentrations and space velocities [44]. Reinecke et al. investigated $\mathrm{CHC}$ over a $\mathrm{Pt} /$ washcoat catalyst. The authors found that the $\mathrm{CHC}$ reaction initiated spontaneously at a temperature of $25^{\circ} \mathrm{C}$ and $\mathrm{H}_{2}$ concentrations of $0.5-4 \mathrm{vol} \%$. However, a temperature gradient of up to $200{ }^{\circ} \mathrm{C}$ throughout the catalyst surface was observed for inlet $\mathrm{H}_{2}$ concentrations of $4 \mathrm{vol} \%$ [45].

Figure $7 \mathrm{~b}$ shows that an average combustion temperature of $162.8 \pm 8.0{ }^{\circ} \mathrm{C}$ was maintained over $530 \mathrm{~h}$ of $\mathrm{CHC}$. Because the experimental setup used for the catalytic fatigue test is open to the atmosphere, the temperature of the ambient air affects the catalyst temperature. Therefore, the temperature profile deviations observed in Figure $7 \mathrm{~b}$ may be ascribed to day/night cycles. Kozhukhova et al. have earlier shown that the combustion temperature of a Pt/AAO catalyst is sensitive toward external airflow, which has a rather significant cooling effect on the catalytic system [30]. In the present study, the external 
airflow interference was significantly reduced by introducing the vertical enclosure along the full length of the catalyst. However, the enclosure did not allow adiabatic investigations, and heat transfer was inevitable.

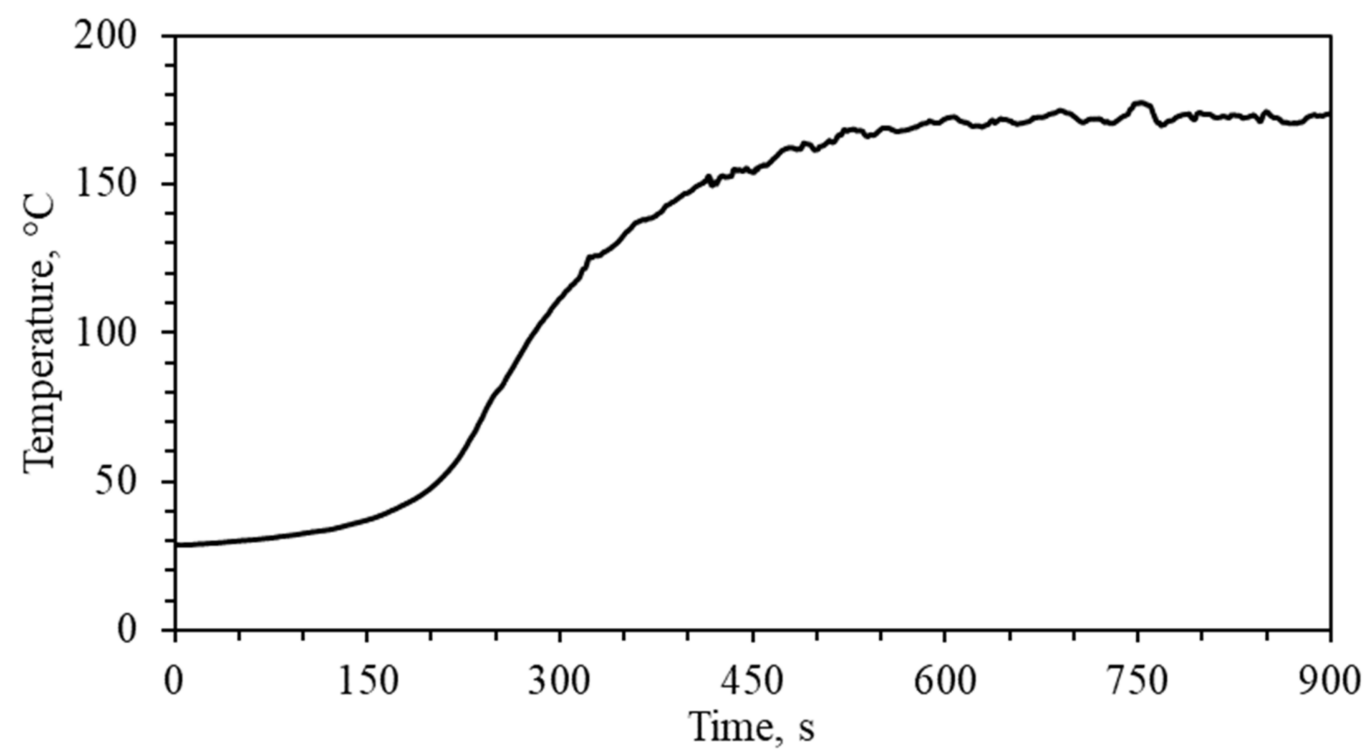

(a)

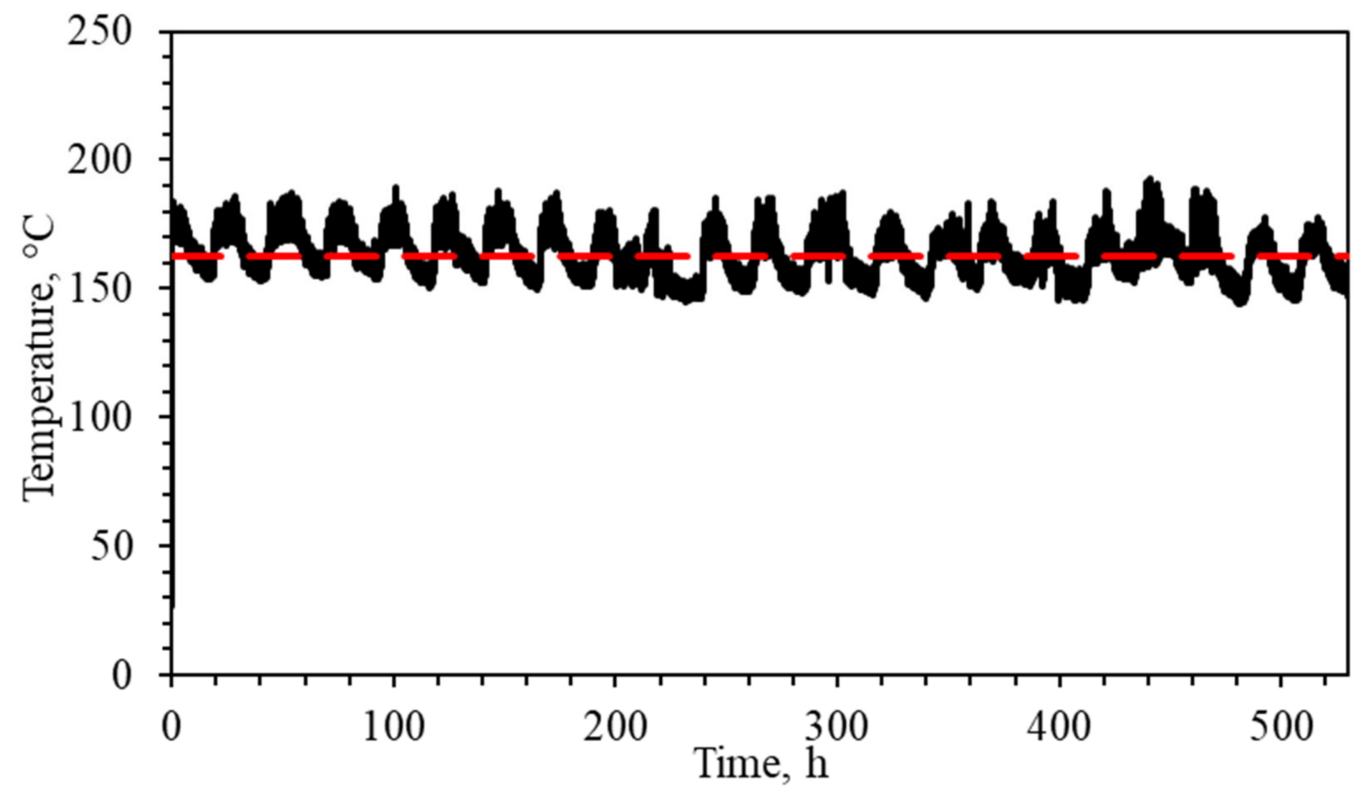

(b)

Figure 7. Combustion temperature profiles of Pt/AAO catalyst: (a) during the first $900 \mathrm{~s}$; (b) $530 \mathrm{~h}$ of $\mathrm{CHC}_{\text {at a }} \mathrm{H}_{2}$ flow rate of $138 \mathrm{NmL} / \mathrm{min}$.

To then investigate any change in the Pt particle size and morphology, the fatigue tested Pt/AAO catalyst was cross-sectioned by FIB and examined using TEM (Figure 8). The average $\mathrm{Pt}$ particle size determined over several TEM images for the spent $\mathrm{Pt} / \mathrm{AAO}$ catalyst was $3.9 \pm 1.9 \mathrm{~nm}$ (based on 220 particles). Therefore, a relatively small increase in particle size occurred (compared with the particles shown in Figure 1b). This was even more evident when considering the morphology of the particles indicated in Figure 8-some evidence of particle aggregation is present, i.e., particles were not as circular as the particles presented in Figure $1 \mathrm{~b}$. This suggests that some Pt aggregation did occur during the 
prolonged $\mathrm{CHC}$ procedure. Furthermore, the formation of $\mathrm{PtO}_{2}$ was likely avoided in the present study. In a study by Olsson and Fridell, a Pt/ $\mathrm{Al}_{2} \mathrm{O}_{3}$ catalyst was analyzed by $\mathrm{X}$-ray photoelectron spectroscopy (XPS) to investigate the formation of Pt oxides after catalyst pretreatment in $\mathrm{H}_{2}, \mathrm{O}_{2}$, and $\mathrm{NO}_{2}$ atmospheres. The formation of $\mathrm{PtO}$ was observed for catalysts treated in $\mathrm{O}_{2}$ and $\mathrm{NO}_{2}$ at 400 and $350{ }^{\circ} \mathrm{C}$, respectively. In addition, the $\mathrm{NO}_{2}$ treated catalysts showed significant $\mathrm{PtO}_{2}$ formation. Traces of $\mathrm{PtO}_{2}$ formation was observed for the catalysts pretreated in $\mathrm{H}_{2}$ at $500{ }^{\circ} \mathrm{C}$ and $\mathrm{O}_{2}$ at $400{ }^{\circ} \mathrm{C}$ [46]. Hwang and $\mathrm{Yeh}$ found $\mathrm{PtO}_{2}$ formation on $\mathrm{Pt} / \mathrm{Al}_{2} \mathrm{O}_{3}$ catalyst when oxidizing in a $5 \mathrm{vol} \% \mathrm{O}_{2}$ atmosphere at temperatures $>300{ }^{\circ} \mathrm{C}$ [47]. In the present study, a $\mathrm{CHC}$ temperature of $<200{ }^{\circ} \mathrm{C}$ was reached during the fatigue test; this suggests that the formation of Pt oxides was absent or insignificant (considering the relatively stable prolonged $\mathrm{CHC}$ temperature, Figure 7). It is proposed that the $\mathrm{Pt} / \mathrm{AAO}$ catalyst prepared here be characterized after $\mathrm{CHC}$ procedures to determine the presence and/or extent of Pt oxidation.

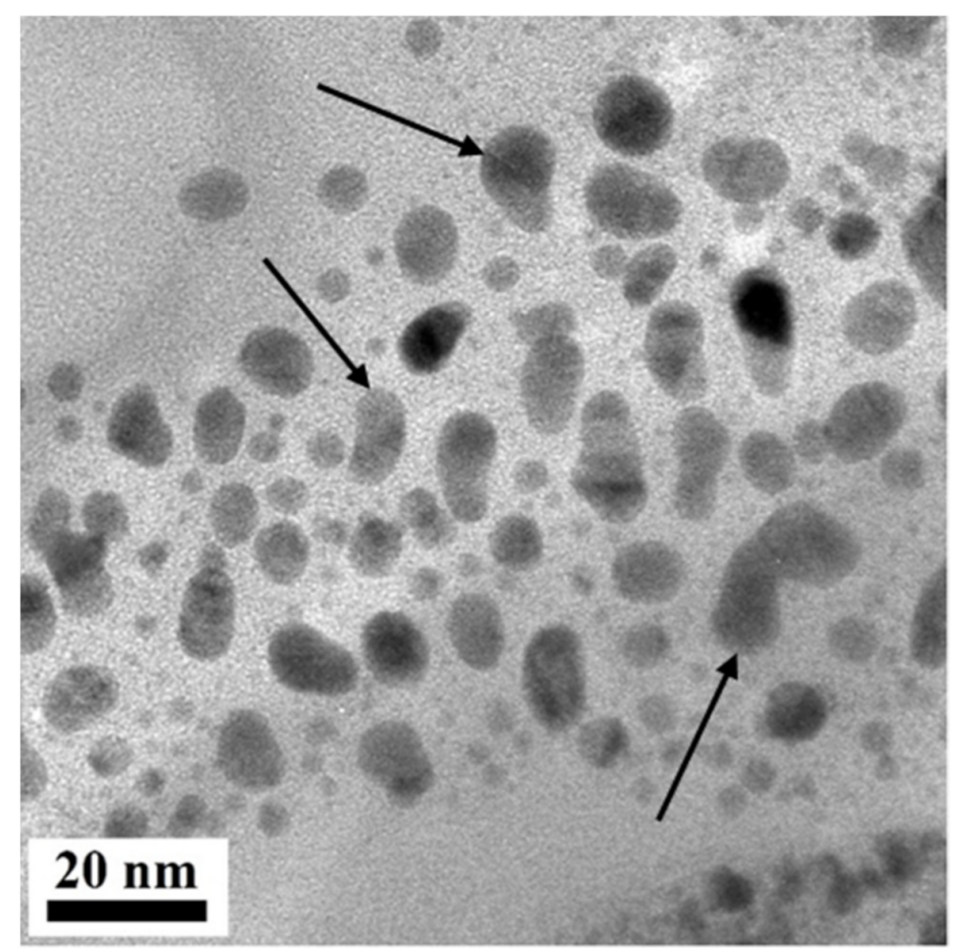

Figure 8. TEM bright-field image of a cross-sectioned Pt/AAO catalyst after $530 \mathrm{~h}$ of $\mathrm{H}_{2}$ exposure.

It is known that Pt and reactive metal-based catalysts are susceptible to thermal degradation, which reduces the catalytic activity of such catalysts $[25,43,48]$. The effect of reactive metal aggregation can be facilitated by exposure to high temperatures $\left(>500{ }^{\circ} \mathrm{C}\right)$ in the presence of oxygen and chlorine; the presence of water vapor increases the rate of aggregation of the supported metal catalyst [26]. Du Preez et al. have reported that the combustion temperature of a Pt/SSM and $\mathrm{Pt} /$ calcined Ti catalyst decreases significantly as Pt aggregation proceeds during the first several hours of CHC [25,43]. One also must consider the bond energy between $\mathrm{Pt}$ and the support material. For instance, it has been found that the aggregation rate for $\mathrm{Ni} / \mathrm{Al}_{2} \mathrm{O}_{3}$ is less than for $\mathrm{Pt} / \mathrm{Al}_{2} \mathrm{O}_{3}$ catalyst due to a greater $\mathrm{Ni}-\mathrm{Al}_{2} \mathrm{O}_{3}$ interaction [26].

Although some Pt aggregates were observed after a CHC reaction time of $530 \mathrm{~h}$ (Figure 8), the effect of $\mathrm{Pt}$ aggregation on the average combustion temperature over this period was not evident (Figure 7). This suggests that the Pt aggregation that occurred was insignificant and did not affect the catalytic activity of the Pt/AAO catalysts. This could be ascribed to the high thermal conductivity of the $\mathrm{Al} / \mathrm{AAO}$ support. 


\subsection{Thermal Distribution of the Pt/AAO Catalyst}

The ability of the catalytic system to distribute heat generated during $\mathrm{CHC}$ is a key parameter when the catalyst is intended to be used in PAR applications. Of importance here is that the low thermal conductivity of the PAR catalytic system may itself cause a selfignition. Uniform temperature distribution is achieved only when exothermic reaction heat is efficiently distributed throughout the entire catalyst. Moreover, localized reactive metal aggregation is prevented in the absence of hotspots; thus, the catalytic activity of a catalyst is preserved. Therefore, the thermal distribution of the catalyst should be investigated before the catalyst is introduced into commercial PARs.

The mechanism involved during $\mathrm{CHC}$ of a Pt/AAO catalyst was presented in an early study by Kozhukhova et al. [28]. They showed that the use of an Al metallic core adjacent to the AAO layer as part of the catalyst support allowed high thermal conductivity of the $\mathrm{Pt} / \mathrm{AAO}$ system for $530 \mathrm{~h}$ of $\mathrm{CHC}$. Due to the absence of hotspots, flashing $\left(\mathrm{H}_{2}\right.$ ignition) would only be possible if the temperature of the entire catalyst surface exceeded the $\mathrm{H}_{2}$ autoignition temperature $\left(585^{\circ} \mathrm{C}\right)$, which is considered an unlikely event.

In the present study, a detailed investigation into the thermal distribution of the $\mathrm{Pt} / \mathrm{AAO}$ catalyst was carried out. To investigate the significance of hotspot formation during $\mathrm{CHC}$ reactions, three samples with nonuniform Pt distribution were prepared. These samples are henceforth referred to as nonuniform catalysts. Catalysts with uniform Pt distribution are defined similarly. Figure 9 a presents an image of the thermal distribution of the uniform and nonuniform catalysts obtained with an IR camera. Figure $9 \mathrm{~b}$ represents the change in catalyst surface temperatures throughout $70 \mathrm{~mm}$ of the catalyst length as a function of $\mathrm{H}_{2}$ exposure time. The two samples on the left and three on the right represent the uniform and nonuniform catalysts, respectively.

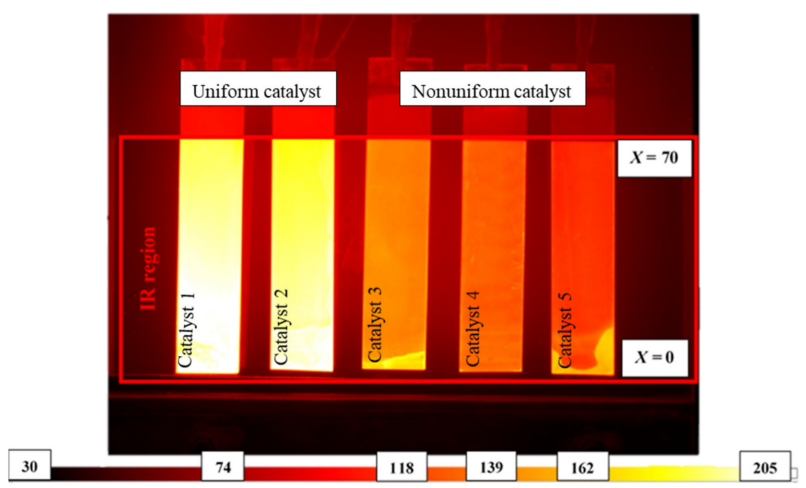

(a)

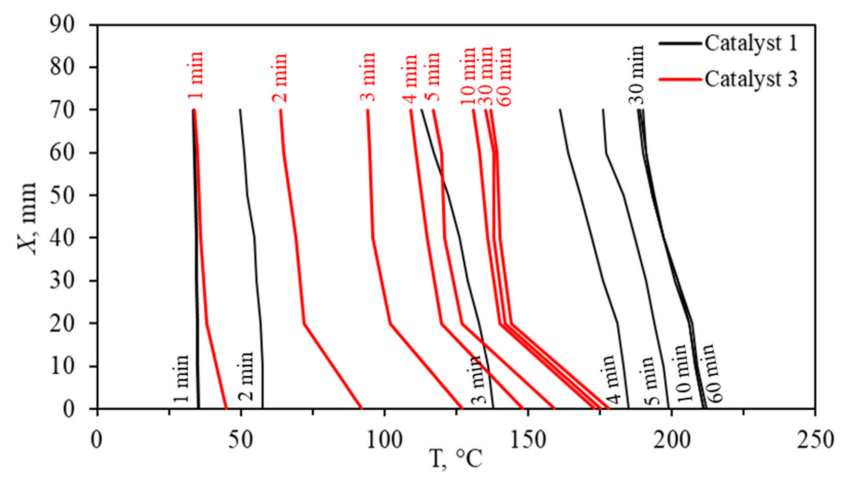

(b)

Figure 9. Infrared (IR) camera temperature map of $\mathrm{Pt} / \mathrm{AAO}$ catalyst at steady-state conditions (a) and the change in catalyst surface temperature as a function of catalyst position (b) in a $3 \mathrm{vol} \% \mathrm{H}_{2} /$ air mixture after $3600 \mathrm{~s}$ of $\mathrm{CHC}$. 
Catalyst surface temperatures are presented on a color scale, ranging from black (low-temperature) to bright yellow (high-temperature), as indicated by the temperature scale bar. The region highlighted with a red rectangle indicates the area captured by the IR camera during the $\mathrm{CHC}$ test.

Figure 9a shows the thermal mappings of the catalysts during steady-state $\mathrm{CHC}$ conditions. The thermal mapping is relatively consistent for the uniform catalysts. This was expected, as the catalyst preparation method applied here allowed a relatively uniform distribution of $\mathrm{Pt}$ throughout the AAO layer. The opposite was observed for the nonuniform catalysts, where the bright yellow areas at the bottom of the images for catalysts 3 and 5 are representative of hotspots. Although catalyst 4 did not include hotspots, the catalyst was prepared with the intent to disrupt uniform Pt distribution. The hotspots presented on the surfaces of catalysts 3 and 5 correlate with higher Pt contents relative to the rest of the catalyst surface, suggesting that a larger fraction of $\mathrm{H}_{2}$ is recombined in this localized area. As mentioned earlier, these hotspots may cause the unintentional ignition of $\mathrm{H}_{2}$ / air mixtures.

Figure $9 \mathrm{~b}$ presents the quantified temperature distribution of the thermal mapping presented in Figure 9a of catalysts 1 and 3. In Figure 9b, $X$ refers to the distance from the bottom of the catalyst, with $X=0$ and $X=70 \mathrm{~mm}$ referring to the bottom and top of the catalyst (as indicated in Figure 9a), respectively. An appreciable temperature increase

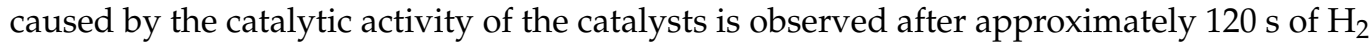
exposure. The temperature of catalysts 1 and 3 was 211 and $173^{\circ} \mathrm{C}$ after $10 \mathrm{~min}$ of $\mathrm{CHC}$, respectively. Of importance is the temperature gradient $(\Delta \mathrm{T})$ over the length of the catalyst (from $X=0$ to $X=70$ ). Catalysts 1 and 3 had $\Delta \mathrm{T}$ of 23 and $42{ }^{\circ} \mathrm{C}$, respectively.

According to Reinecke et al., the exothermal $\mathrm{CHC}$ reaction mainly occurs in the very first surface section, resulting in a surface temperature gradient from the bottom to the top of the catalyst. A significant temperature gradient of $200{ }^{\circ} \mathrm{C}$ was found for the stainless steel $\mathrm{Pt} /$ washcoat catalytic material [45]. Malakhov et al. observed a temperature gradient of $341.2^{\circ} \mathrm{C}$ over a tubular ceramic $\mathrm{Pt} / \mathrm{Al}_{2} \mathrm{O}_{3}$ washcoat catalyst [2]. By comparison, a $\Delta \mathrm{T}$ of $23^{\circ} \mathrm{C}$ for the uniform catalyst over a distance of $70 \mathrm{~mm}$ is relatively insignificant. Moreover, a $\Delta \mathrm{T}$ of $42{ }^{\circ} \mathrm{C}$ in a nonideal ("worst-case") scenario is indicative of the highly effective thermal conductivity of the $\mathrm{Al}$ core present in the $\mathrm{Pt} / \mathrm{AAO}$ catalysts prepared in this study. Based on the observed $\Delta \mathrm{T}$, and because it is significantly lower than commercially employed catalysts, it is proposed that the thermal distribution of the $\mathrm{Pt} / \mathrm{AAO}$ catalyst at explosive $\mathrm{H}_{2}$ concentrations ( $>4 \mathrm{vol} \%$ ) should be investigated in future research.

\subsection{CFD Calculations}

Detailed research on catalytic recombiners is usually required to investigate the interactions of reaction kinetics, temperature distribution, and heat and mass transfer. The application of CFD modeling in hydrogen safety applications may be very helpful, especially when the research needs to be conducted under conditions close to the accident ones (accident conditions) (e.g., the concentration of $\mathrm{H}_{2}>4 \mathrm{vol} \%$, high $\mathrm{H}_{2}$ flow rate). In the present study, a model was created to investigate temperature distribution throughout the $\mathrm{Pt} / \mathrm{AAO}$ catalyst under the same conditions that were used during the thermal mapping shown in Figure $9 \mathrm{a}\left(3 \mathrm{vol} \% \mathrm{H}_{2}\right)$. If high predictability of the results is obtained, the model may be applied in further research-for example, determining the thermal conductivity of the $\mathrm{Pt} / \mathrm{AAO}$ catalyst at $\mathrm{H}_{2}$ concentrations $>3 \mathrm{vol} \%$.

Figure 10a presents the thermal distribution of uniform Pt/AAO catalysts obtained at steady-state conditions using a CFD numerical tool. Figure 10b shows the change in Pt/AAO catalyst surface temperatures throughout $90 \mathrm{~mm}$ of the catalyst length at steady-state conditions. 


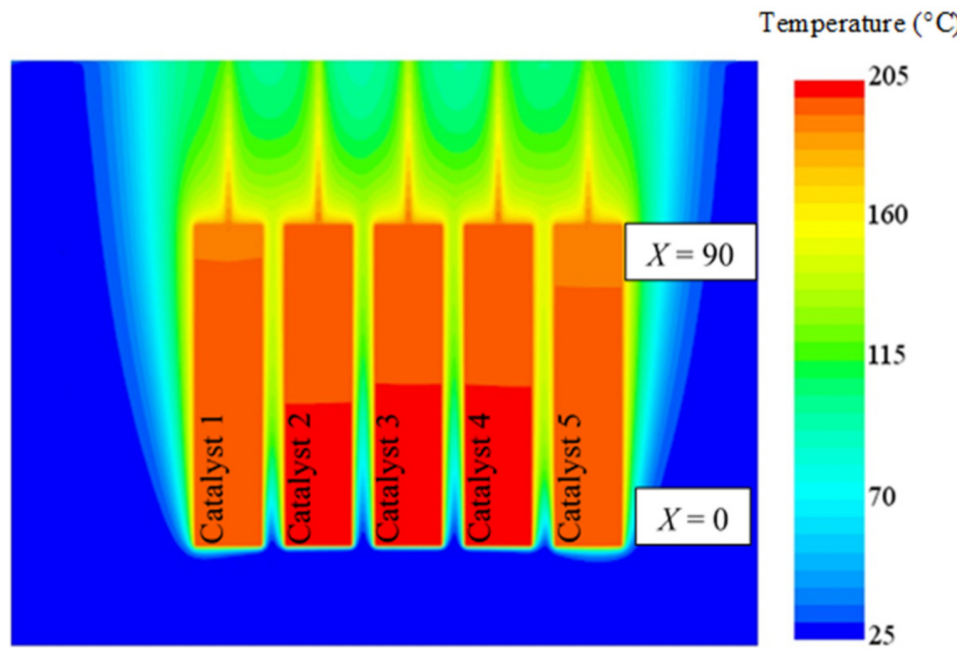

(a)

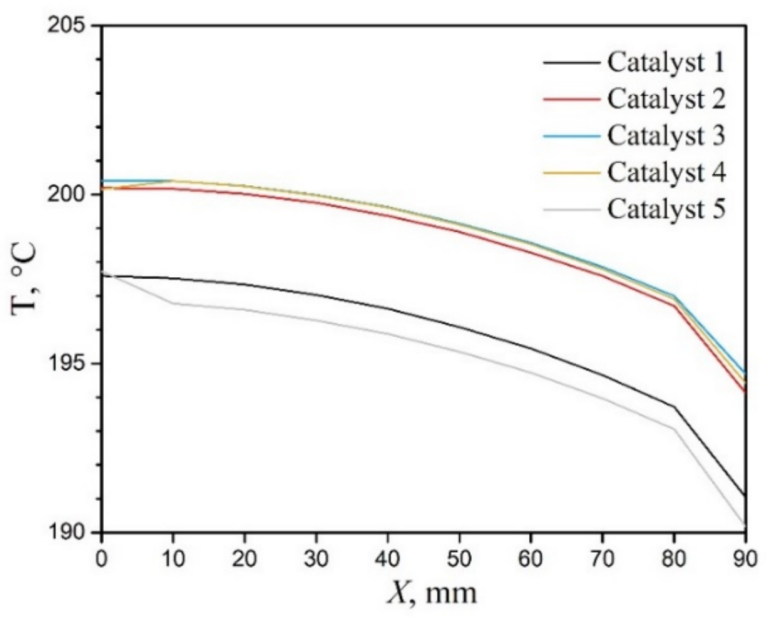

(b)

Figure 10. IR camera temperature map of $\mathrm{Pt} / \mathrm{AAO}$ catalyst obtained at steady-state conditions (a) and the change in $\mathrm{Pt} / \mathrm{AAO}$ catalyst surface temperature as a function of catalyst "position" $X(\mathbf{b})$, determined by computational fluid dynamics (CFD) simulation.

Figure 10a shows that uniform temperature distribution throughout the samples was obtained. However, a relatively small temperature decrease in catalyst surface temperature from the bottom to the top of the catalyst was observed. Figure $10 \mathrm{~b}$ shows that the change in catalyst surface temperature decreased from $198,200,200,200$, and $198^{\circ} \mathrm{C}$ to 191,194 , 195,194 , and $190{ }^{\circ} \mathrm{C}$ for catalysts $1-5$, respectively. The average $\Delta \mathrm{T}$ throughout $90 \mathrm{~mm}$ and $70 \mathrm{~mm}$ of the catalyst surface was 7 and $3{ }^{\circ} \mathrm{C}$, respectively. The numerical model did not assume any disorder of $\mathrm{Pt}$ particle distribution on the support surface that may occur during a real catalyst preparation procedure. Therefore, the difference in $\Delta \mathrm{T}$ determined experimentally and by simulation ( 23 and $3{ }^{\circ} \mathrm{C}$, respectively) may be ascribed to the actual distribution of $\mathrm{Pt}$ on the AAO surface of the $\mathrm{Pt} / \mathrm{AAO}$ catalysts prepared in this study. Figure 11 presents a distribution of $\mathrm{H}_{2}$ throughout the catalyst surface obtained at steady-state conditions. 


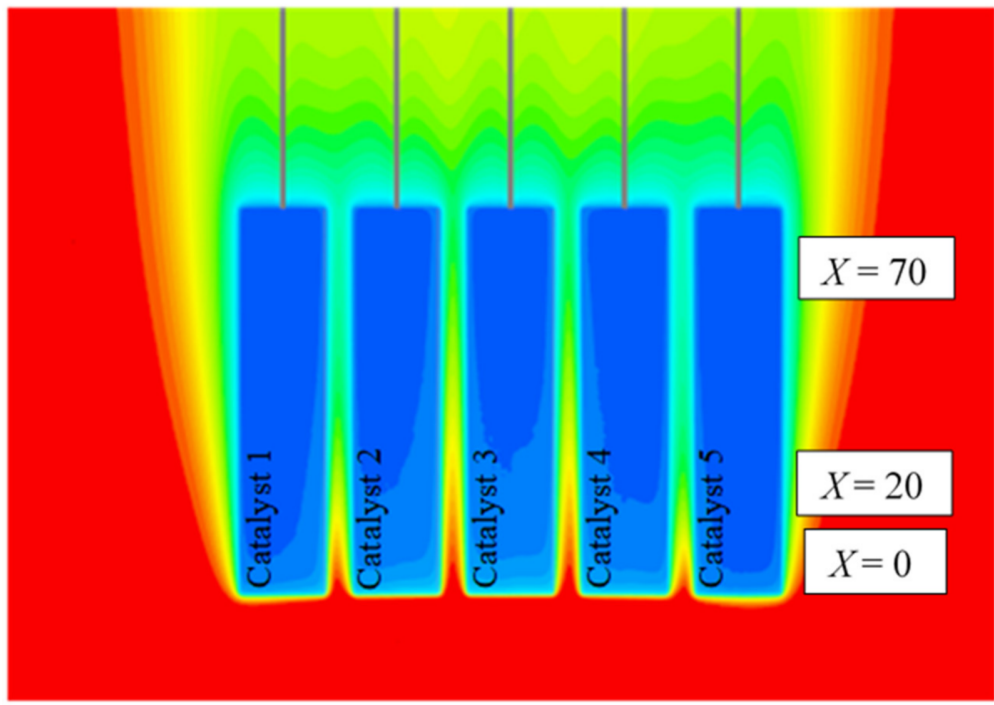

Mole fraction of $\mathrm{H}_{2}$

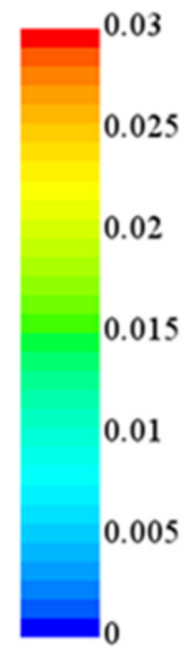

Figure 11. $\mathrm{H}_{2}$ distribution map of $\mathrm{Pt} / \mathrm{AAO}$ catalyst obtained at steady-state conditions, determined by CFD simulation.

Figure 11 shows that the $\mathrm{H}_{2}$ concentration over the catalyst surface was relatively low, which suggests that $\mathrm{H}_{2}$ recombination occurs rapidly on the surface of $\mathrm{Pt} / \mathrm{AAO}$ catalysts. Two observations are made from Figure 11: first, the $\mathrm{H}_{2}$ concentration at the bottom of the catalyst $(X=0)$ is higher when compared to $X>0$ and, second, the $\mathrm{H}_{2}$ concentration gradients of catalysts 2-4 were dissimilar to those of catalysts 1 and 5 . Both of these observations could be ascribed to the presence of local flow fluctuations throughout the recombiner section [49]. To investigate this, the linear velocity at the local points of the gas mixture present for catalysts $1-5$ at positions $X=0,20$, and 70 are shown in Table 2 . The change in the linear velocity at $X>70 \mathrm{~mm}$ was negligible. Therefore, these values were not included for further consideration.

Table 2. Local linear velocity of a $\mathrm{H}_{2}$ /air mixture, determined by CFD simulation.

\begin{tabular}{cccccc}
\hline \multirow{2}{*}{$\mathbf{, ~ m m}$} & \multicolumn{5}{c}{$\mathbf{H}_{\mathbf{2}}$ /Air Mixture Local Linear Velocity, $\mathbf{~ m / s}$} \\
\cline { 2 - 6 } & Catalyst $\mathbf{1}$ & Catalyst 2 & Catalyst 3 & Catalyst 4 & Catalyst 5 \\
\hline 0 & 0.037 & 0.147 & 0.219 & 0.182 & 0.053 \\
20 & 0.049 & 0.141 & 0.199 & 0.172 & 0.062 \\
70 & 0.075 & 0.131 & 0.153 & 0.142 & 0.085 \\
\hline
\end{tabular}

Table 2 shows that the local linear velocity for catalysts $2-4$ decreased with increasing position $X$ from 0 to $70 \mathrm{~mm}$, while the linear velocity increased for catalysts 1 and 5 . The difference between the flow rates for the catalysts may be ascribed to the design of the recombiner section. The mixing plate present in the recombiner section testing station (see Figure 12) was included to allow a uniform $\mathrm{H}_{2}$ /air mixture, although it may also influence flow distribution.

The presence of flow fluctuations is common considering the differing geometry of PARs and may be ascribed to dissimilar linear velocities throughout a recombiner framework [2]. A slight decrease in $\mathrm{H}_{2}$ concentration for catalysts 1 and 5, however, may be related to the presence of natural convection when the mass transfer occurs with a flow of heat produced by $\mathrm{CHC}$. In conclusion, from the data presented in Figure 11 and Table 2, the authors assume that under the explored conditions in the present study, the $\mathrm{CHC}$ occurs to an incomplete extent at $X=0$. Figure 11 further shows that a near-zero concentration of $\mathrm{H}_{2}$ was obtained at $X=70$, suggesting that, for the investigated catalyst, near-complete $\mathrm{H}_{2}$ recombination occurred throughout the catalyst surface. 


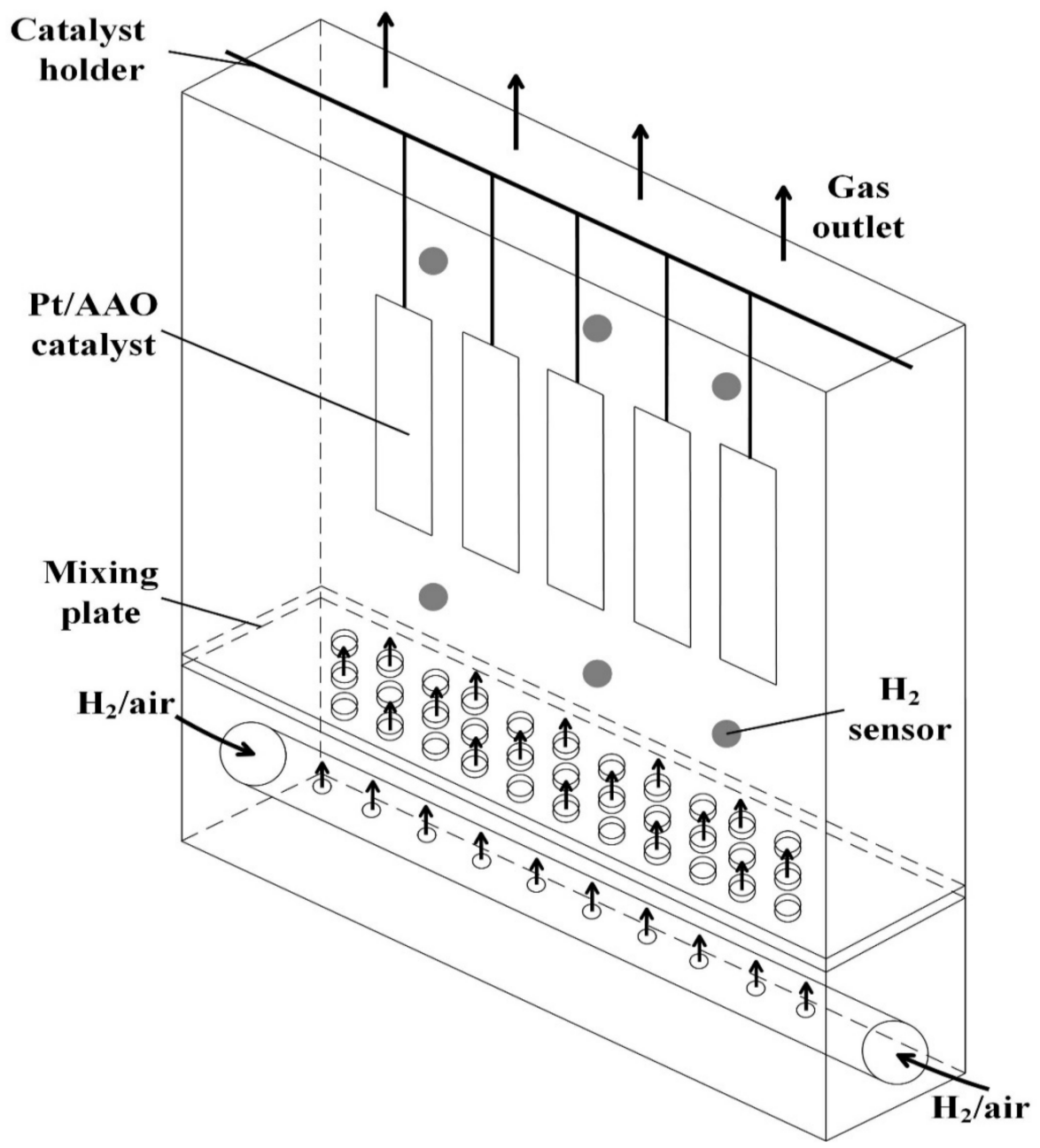

Figure 12. Schematic of the experimental setup used to determine the Pt/anodized aluminum oxide (AAO) catalytic activity and thermal distribution of the catalyst section.

\section{Experimental}

\subsection{Preparation of Pt/AAO Catalyst and Its Characterization}

The AAO support was prepared by two-step anodization of $0.2 \mathrm{~cm}$-thick $\mathrm{Al}$ alloy plates sized $2 \mathrm{~cm} \times 9 \mathrm{~cm}$ (Al6082 alloy, 97.5\% Al, Aluminium and Metal Traders CC, Welkom, South Africa). Each plate included a $1 \mathrm{~cm}$ handle, which was not anodized. The anodization procedure has been described in early studies by Kozhukhova et al. [50,51]. In short, the sample surfaces were degreased by ultrasonication in acetone, rinsed with deionized water, and then subjected to electropolishing in a mixture of $\mathrm{HClO}_{4}$ (SigmaAldrich, Schnelldorf, Germany) and ethanol (Rochelle Chemicals and Lab Equipment, Johannesburg, South Africa) at a voltage of $20 \mathrm{~V}$ for $1 \mathrm{~min}$. Next, two-step anodization was carried out in a $0.3 \mathrm{M}$ oxalic acid (Rochelle Chemicals and Lab Equipment, Johannesburg, South Africa) solution. As described in an earlier study of Kozhukhova et al., AAO formed in oxalic acid at a temperature of $30^{\circ} \mathrm{C}$ and voltage of $60 \mathrm{~V}$ had a relatively ordered pore distribution when the anodization time of the second step was kept to $1 \mathrm{~h} \mathrm{[50].} \mathrm{Therefore,}$ we selected this AAO layer to use as catalyst support in the present study. Accordingly, the first anodization step was performed at a temperature of $30^{\circ} \mathrm{C}$ and a voltage of $30 \mathrm{~V}$ for $30 \mathrm{~min}$. Thereafter, the AAO layer formed during the first step was removed by submerging the sample in a mixture of $5 \% \mathrm{H}_{3} \mathrm{PO}_{4}$ (Sigma-Aldrich, Mainland, China) and $1.8 \% \mathrm{CrO}_{3}$ (Sigma-Aldrich, Modderfontein, South Africa) at $60{ }^{\circ} \mathrm{C}$ for $5 \mathrm{~min}$. The second anodization step was performed at a temperature of $30^{\circ} \mathrm{C}$ and a voltage of $60 \mathrm{~V}$ for 1 or $4 \mathrm{~h}$. Isothermal conditions were maintained using a refrigerating-heating circulating 
system (Julabo, CORIO CD-200 F, Seelbach, Germany). An adjustable DC power supply (Elektro-Automatik, EA-PSI 5200-10A, Morfelden-Walldorf, Germany) with a voltage range of 0-200 V and a current range of 0-10 A was used to control the applied voltage.

The $\mathrm{Pt} / \mathrm{AAO}$ catalyst was prepared by the incipient wet impregnation method. This method includes the immersion of samples in a $22.8 \mathrm{~g} / \mathrm{L}$ ethanol-based hexachloroplatinic acid solution $\left(\mathrm{H}_{2} \mathrm{PtCl}_{6} \cdot 6 \mathrm{H}_{2} \mathrm{O}\right.$, Sigma-Aldrich, Milano, Italy) for $4 \mathrm{~h}$. Ethanol was used as the solvent to prevent AAO layer dissolution [28]. Next, samples were dried in ambient air, and $\mathrm{Pt}$ was reduced in a hydrogen atmosphere at $350^{\circ} \mathrm{C}$ for $2 \mathrm{~h}$. A vertical tube furnace (CTF 12, Carbolite Gero, Derbyshire, England) was used for the reduction procedure.

The morphology of AAO samples was characterized using an FEI Quanta FEG 250 field emission gun scanning electron microscope (Thermo Fisher Scientific, Waltham, MA, USA). Before SEM analysis, the AAO samples were coated with a thin layer of carbon using a carbon coater (Emscope TB 500, UK). The morphological characteristics (diameter of pores $\mathrm{D}_{\mathrm{p}}$, interpore distance $\mathrm{D}_{\mathrm{c}}$, pore density $n$, and porosity $P$ ) were determined from SEM images using the ImageJ program.

The Pt/AAO catalyst was analyzed by TEM before and after being subjected to prolonged CHC. Before TEM analysis, the Pt/AAO catalysts were sectioned by a focused ion beam (FIB). FIB lamellas were prepared using an FEI Helios Nanolab 650 dual-beam scanning electron microscope (Thermo Fisher Scientific, Waltham, MA, USA). TEM analyses were then carried out using a Technai F20 FEI instrument (Thermo Fisher Scientific, Waltham, MA, USA).

\subsection{Catalytic Test in the Recombiner Section Testing Station}

The prepared $\mathrm{Pt} / \mathrm{AAO}$ catalysts were tested as a catalyst section in an in-housedeveloped recombiner section testing station (Hydrogen South Africa Infrastructure, Potchefstroom, South Africa). The schematic of the experimental setup is presented in Figure 12.

The testing station represents a rectangular box allowing a vertical flow of an $\mathrm{H}_{2}$ / air mixture under defined conditions (e.g., flow rate, $\mathrm{H}_{2} /$ air inlet volume ratio). Digital thermal massflow controllers (EL-FLOW F-201AV, Bronkhorst, The Netherlands) were used to control the inlet concentrations of $\mathrm{H}_{2}$ and air. High-purity $\mathrm{H}_{2}\left(>99.9 \% \mathrm{H}_{2}\right.$, Hydrogen South Africa Infrastructure, Potchefstroom, South Africa) and compressed air were used as the inlet gas mixture. The $\mathrm{H}_{2}$ /air mixture with a $\mathrm{H}_{2}$ concentration of $0.5-4 \mathrm{vol} \%$ was fed into a pipe at the bottom of the experimental setup at an inlet flow velocity of $9.5 \mathrm{~m} / \mathrm{s}$. A relatively uniform gas flow distribution was achieved by using a mixing plate placed above the inlet pipe; the mixing plate had uniformly distributed holes. Thereafter, the gas mixture reaches the catalyst section, where the recombination reaction occurs. The reaction products (water vapor) and any unreacted $\mathrm{H}_{2}$ pass through the gas outlet at the top of the experimental setup. In this study, the catalyst section consisted of five $\mathrm{Pt} / \mathrm{AAO}$ catalysts $(10 \times 2 \mathrm{~cm}$ each) placed inside the recombiner testing station. Catalysts were placed vertically and spaced $1 \mathrm{~cm}$ from each other. The catalyst section was fixed $8 \mathrm{~cm}$ above the mixing plate using clamps.

Six $\mathrm{H}_{2}$ sensors (Model XEN-5320, Xensor Integration, Delfgauw, The Netherlands) were positioned inside the experimental setup to evaluate the $\mathrm{H}_{2}$ content before and after CHC. Measurements were logged every $1 \mathrm{~s}$, using LabVIEW software. All combustion procedures were performed in triplicate, and the average values are presented.

The thermal distribution of the catalytic surface was recorded using a high-resolution IR camera (M100hd, Telops, Ontario, Canada). The camera was fitted with a lens designated to capture thermal data in the temperature range $0-325^{\circ} \mathrm{C}$. A synthetic sapphire glass panel was installed in the testing recombiner station to enable the camera to capture thermal data. Thermal data were recorded every $1 \mathrm{~s}$, using Reveal IR software (v. 1.7.0) (Telops, ON, Canada). 


\subsection{Catalyst Fatigue Test}

The $\mathrm{Pt} / \mathrm{AAO}$ catalyst was subjected to a fatigue procedure to evaluate the stability and catalytic activity of the catalyst during prolonged high-temperature $\mathrm{CHC}$. A similar fatigue procedure was applied in an earlier study by Kozhukhova et al. [28]. For the fatigue test, the vertically placed $\mathrm{Pt} / \mathrm{AAO}$ catalyst was exposed to a flow of a $\mathrm{H}_{2}$ /air mixture with a high $\mathrm{H}_{2}$ content ( $138 \mathrm{NmL} / \mathrm{min}$; instrument maximum flow rate). $\mathrm{H}_{2}$ was supplied using an in-house-developed electrolytic hydrogen generator (Hydrogen South Africa Infrastructure, Potchefstroom, South Africa). The sample was placed $3 \mathrm{~mm}$ above the hydrogen nozzle, allowing premixing of $\mathrm{H}_{2}$ and air before it reached the catalyst surface. The temperature of the catalyst surface was measured at the center of the sample using a K-type thermocouple. Thermal measurements were recorded every $1 \mathrm{~s}$. The fatigue test was performed for $530 \mathrm{~h}$.

\subsection{CFD Calculations}

The computational domain was created in STAR-CCM+ (Siemens PLM Software, TX, USA) as a vertical rectangular box with the dimensions $24.2 \times 4.55 \times 28.0 \mathrm{~cm}$ (length $\times$ width $\times$ height). These dimensions matched the recombiner section testing station. The computational mesh was generated by a polyhedral cell based on a minimum cell size of $4.0 \mathrm{~mm}$. The refinement by surface and volumetric mesh control was applied around the catalyst area. The total number of cells was approximately 3.3 million. Steadystate analyses were performed for all calculations. A realizable k-epsilon $(k-\varepsilon)$ model with a two-layer approach was used for a turbulent flow simulation [52]. Reynolds-averaged Navier-Stokes equations were solved to simulate a gas flow. An initial temperature of $25^{\circ} \mathrm{C}$ and pressure of $10^{5} \mathrm{~Pa}$ were set. A detailed mechanism of the $\mathrm{CHC}$ reaction on a $\mathrm{Pt} / \mathrm{AAO}$ catalyst was used in previous work [53]. The Pt/AAO catalyst plates were $90 \mathrm{~mm}$ in length and had Pt active sites over the entire surface. The site density for $\mathrm{Pt}$ was taken as $2.7 \times 10^{-8} \mathrm{kmol} / \mathrm{m}^{2}[53]$.

\section{Conclusions}

In this study, a Pt/AAO catalyst was prepared and evaluated for passive autocatalytic recombination of hydrogen. The AAO support was prepared by anodizing a low Al purity $\mathrm{Al}$ alloy Al6082 in oxalic acid. The metallic $\mathrm{Al}$ core was preserved during the anodization procedure, and it acted as a thermal conduit during $\mathrm{CHC}$ reactions, affording a $\mathrm{Pt} / \mathrm{AAO}$ catalyst with high thermal conductivity. The prepared $\mathrm{Pt} / \mathrm{AAO}$ catalyst had an average $\mathrm{Pt}$ particle size of $3.0 \pm 0.6 \mathrm{~nm}$ and an $\mathrm{E}_{\mathrm{a}}$ of $19.2 \mathrm{~kJ} / \mathrm{mol}$ for CHC. The catalyst maintained a combustion temperature of $162.8 \pm 8.0^{\circ} \mathrm{C}$ for $530 \mathrm{~h}$ at a $\mathrm{H}_{2}$ flow rate of $138 \mathrm{NmL} / \mathrm{min}$. Although some Pt aggregation was observed after the aforementioned $530 \mathrm{~h}$ of $\mathrm{CHC}$, the significance thereof was not evident, as a decrease in the combustion temperature during prolonged $\mathrm{CHC}$ was not observed. Thermal imaging revealed a temperature gradient of $23{ }^{\circ} \mathrm{C}$ over $70 \mathrm{~mm}$ of the catalyst surface. To simulate a nonideal ("worst-case") scenario, $\mathrm{Pt} / \mathrm{AAO}$ catalysts were prepared to contain hotspots. They were formed by nonuniform $\mathrm{Pt}$ distribution and had a temperature gradient of $42{ }^{\circ} \mathrm{C}$ over $70 \mathrm{~mm}$ of the catalyst surface. In both cases, the reported temperature gradients were well below those of catalysts used for PARs reported in the literature. CFD modeling revealed a $3{ }^{\circ} \mathrm{C}$ temperature gradient; the CFD model assumed perfect Pt distribution over the catalyst surface. Moreover, CFD calculations showed that although flow fluctuation was present within a simulated recombiner section, which is inherent for any PAR, the Pt/AAO could combust the majority of the $\mathrm{H}_{2}$ introduced to the recombiner section. However, the concentration of $\mathrm{H}_{2}$ in the case of accidents in NPPs and mines can reach values much higher than that considered in the present study $\left(1-4 \mathrm{vol} \%\right.$ of $\left.\mathrm{H}_{2}\right)$. Considering that, future research should be focused on the investigation of the $\mathrm{Pt} / \mathrm{AAO}$ catalyst for $\mathrm{CHC}$ at higher inlet concentrations of $\mathrm{H}_{2}$ (>4 vol\%). In conclusion, due to the high thermal conductivity of the Pt/AAO catalyst, its fast self-start characteristic, and high stability, the authors assume that the catalyst reported in this study can be used for PAR application. 
Author Contributions: Conceptualization, S.P.d.P.; methodology, A.E.K.; supervision, S.P.d.P. and D.G.B.; investigation, A.E.K. and A.A.M.; formal analysis and data curation, A.E.K., A.A.M., S.P.d.P., and D.G.B.; Writing-Original draft preparation, A.E.K. and A.A.M.; Writing-Review and editing, S.P.d.P., and D.G.B.; funding acquisition, D.G.B. All authors have read and agreed to the published version of the manuscript.

Funding: This work was supported by the Department of Science and Innovation (DSI) and HySA Infrastructure in South Africa, through their financial support KP5 program and NRF grants $(104687,119004)$.

Acknowledgments: We would like to thank S.P. Oelofse and T. Paarlberg for designing and constructing the PAR testing station, C. Martinson for calibrating the hydrogen sensors, and N. Engelbrecht for assisting with the IR camera.

Conflicts of Interest: The authors declare no conflict of interest

\section{References}

1. Park, J.-W.; Koh, B.-R.; Suh, K.Y. Demonstrative testing of honeycomb passive autocatalytic recombiner for nuclear power plant. Nucl. Eng. Des. 2011, 241, 4280-4288. [CrossRef]

2. Malakhov, A.A.; du Toit, M.H.; Du Preez, S.P.; Avdeenkov, A.V.; Bessarabov, D.G. Temperature profile mapping over a catalytic unit of a hydrogen passive autocatalytic recombiner: An experimental and computational fluid dynamics study. Energy Fuels 2020, 34, 11637-11649. [CrossRef]

3. Prabhudharwadkar, D.M.; Aghalayam, P.A.; Iyer, K.N. Simulation of hydrogen mitigation in catalytic recombiner: Part-I: Surface chemistry modelling. Nucl. Eng. Des. 2011, 241, 1746-1757. [CrossRef]

4. Klauck, M.; Reinecke, E.-A.; Kelm, S.; Meynet, N.; Bentaïb, A.; Allelein, H.-J. Passive auto-catalytic recombiners operation in the presence of hydrogen and carbon monoxide: Experimental study and model development. Nucl. Eng. Des. 2014, 266, 137-147. [CrossRef]

5. Bockris, J.O.M. The hydrogen economy: Its history. Int. J. Hydrogen Energy 2013, 38, 2579-2588. [CrossRef]

6. Haruta, M.; Souma, Y.; Sano, H. Catalytic combustion of hydrogen-II. An experimental investigation of fundamental conditions for burner design. Int. J. Hydrogen Energy 1982, 7, 729-736. [CrossRef]

7. Wierzba, I.; Depiak, A. Catalytic oxidation of lean homogeneous mixtures of hydrogen/hydrogen-methane in air. Int. J. Hydrogen Energy 2004, 29, 1303-1307. [CrossRef]

8. Choi, W.; Kwon, S.; Shin, H.D. Combustion characteristics of hydrogen-air premixed gas in a sub-millimeter scale catalytic combustor. Int. J. Hydrogen Energy 2008, 33, 2400-2408. [CrossRef]

9. Haruta, M.; Sano, H. Catalytic combustion of hydrogen-IV. Fabrication of prototype catalytic heaters and their operating properties. Int. J. Hydrogen Energy 1982, 7, 801-807. [CrossRef]

10. Haruta, M.; Sano, H. Catalytic combustion of hydrogen I-Its role in hydrogen utilization system and screening of catalyst materials. Int. J. Hydrogen Energy 1981, 6, 601-608. [CrossRef]

11. Zaitsev, N.K.; Dvorkin, V.I.; Melnikov, P.V.; Kozhukhova, A.E. A dissolved oxygen analyzer with an optical sensor. J. Anal. Chem. 2018, 73, 102-108. [CrossRef]

12. Melnikov, P.V.; Kozhukhova, A.E.; Naumova, A.O.; Yashtulov, N.A.; Zaitsev, N.K. Optical Analyzer for Continuous Monitoring of Dissolved Oxygen in Aviation Fuel and Other Non-aqueous Media. Int. J. Eng. 2019, 32, 641-646.

13. Alexandrovskaya, A.Y.; Melnikov, P.V.; Safonov, A.V.; Naumova, A.O.; Zaytsev, N.K. A comprehensive study of the resistance to biofouling of different polymers for optical oxygen sensors. The advantage of the novel fluorinated composite based on core-dye-shell structure. Mater. Today Commun. 2020, 23, 100916. [CrossRef]

14. Jung, N.; Chung, D.Y.; Ryu, J.; Yoo, S.J.; Sung, Y.-E. Pt-based nanoarchitecture and catalyst design for fuel cell applications. Nano Today 2014, 9, 433-456. [CrossRef]

15. Gasteiger, H.A.; Kocha, S.S.; Sompalli, B.; Wagner, F.T. Activity benchmarks and requirements for Pt, Pt-alloy, and non-Pt oxygen reduction catalysts for PEMFCs. Appl. Catal. B 2005, 56, 9-35. [CrossRef]

16. Ströbel, R.; Oszcipok, M.; Fasil, M.; Rohland, B.; Jörissen, L.; Garche, J. The compression of hydrogen in an electrochemical cell based on a PE fuel cell design. J. Power Sources 2002, 105, 208-215. [CrossRef]

17. Rohland, B.; Eberle, K.; Ströbel, R.; Scholta, J.; Garche, J. Electrochemical hydrogen compressor. Electrochim. Acta 1998, 43, 3841-3846. [CrossRef]

18. Mercea, J.; Grecu, E.; Fodor, T.; Kreibik, S. Catalytic combustor for hydrogen. Int. J. Hydrogen Energy 1982, 7, 483-487. [CrossRef]

19. Inui, T.; Miyamoto, Y.; Takegami, Y. Low temperature oxidation of hydrogen enhanced by spillover on a nickel-based composite catalyst. In Spillover of Adsorbed Species; Pajonk, G.M., Teichner, S.J., Germain, J.E., Eds.; Elsevier, Studies in Surface Science and Catalysis: Amsterdam, The Netherlands, 1983; pp. 181-190.

20. Deshpande, P.; Madras, G. Noble metal ionic sites for catalytic hydrogen combustion: Spectroscopic insights. Phys. Chem. Chem. Phys. 2010, 13, 708-718. [CrossRef] 
21. Hanson, F.V.; Boudart, M. The reaction between H2 and O2 over supported platinum catalysts. J. Catal. 1978, 53, 56-67. [CrossRef]

22. Kramer, J.F.; Reihani, S.-A.S.; Jackson, G.S. Low-temperature combustion of hydrogen on supported Pd catalysts. Proc. Combust. Inst. 2002, 29, 989-996. [CrossRef]

23. Fernández, A.; Arzac, G.M.; Vogt, U.F.; Hosoglu, F.; Borgschulte, A.; de Haro, M.C.J.; Montes, O.; Züttel, A. Investigation of a Pt containing washcoat on $\mathrm{SiC}$ foam for hydrogen combustion applications. Appl. Catal. B Environ. 2016, 180, 336-343. [CrossRef]

24. Fumey, B.; Buetler, T.; Vogt, U.F. Ultra-low NOx emissions from catalytic hydrogen combustion. Appl. Energy 2018, 213, 334-342. [CrossRef]

25. Du Preez, S.P.; Jones, D.R.; Bessarabov, D.G.; Falch, A.; das Neves Quaresma, C.M.; Dunnill, C.W. Development of a Pt/stainless steel mesh catalyst and its application in catalytic hydrogen combustion. Int. J. Hydrogen Energy 2019, 44, 27094-27106. [CrossRef]

26. Bartholomew, C.H. Mechanisms of catalyst deactivation. Appl. Catal. A 2001, 212, 17-60. [CrossRef]

27. Schefer, R.W.; Robben, F.; Cheng, R.K. Catalyzed combustion of H2/air mixtures in a flat-plate boundary layer: I. Experimental results. Combust. Flame 1980, 38, 51-63. [CrossRef]

28. Kozhukhova, A.E.; Du Preez, S.P.; Shuro, I.; Bessarabov, D.G. Development of a low purity aluminum alloy (Al6082) anodization process and its application as a platinum-based catalyst in catalytic hydrogen combustion. Surf. Coat. Tech. 2020, $404,126483$. [CrossRef]

29. Siemens. STAR CCM+ User Guide Version 12.04; CD-Adapco: New York, NY, USA, 2017.

30. Ostermaier, J.J.; Katzer, J.R.; Manogue, W.H. Platinum catalyst deactivation in low-temperature ammonia oxidation reactions: I. Oxidation of ammonia by molecular oxygen. J. Catal. 1976, 41, 277-292. [CrossRef]

31. Nguyen, V.N.; Deja, R.; Peters, R.; Blum, L.; Stolten, D. Study of the catalytic combustion of lean hydrogen-air mixtures in a monolith reactor. Int. J. Hydrogen Energy 2018, 43, 17520-17530. [CrossRef]

32. Joshi, S.Y.; Ren, Y.; Harold, M.P.; Balakotaiah, V. Determination of kinetics and controlling regimes for $\mathrm{H} 2$ oxidation on Pt/Al2O3 monolithic catalyst using high space velocity experiments. Appl. Catal. B Environ 2011, 102, 484-495. [CrossRef]

33. Younis, L.B. Modelling of hydrogen oxidation within catalytic packed bed reactor. J. Energy Inst. 2006, 79, 222-227. [CrossRef]

34. Bhatia, D.; Harold, M.P.; Balakotaiah, V. Kinetic and bifurcation analysis of the cooxidation of CO and H2 in catalytic monolith reactors. Chem. Eng. Sci. 2009, 64, 1544-1558. [CrossRef]

35. Rui, Z.; Chen, C.; Lu, Y.; Ji, H. Anodic alumina supported Pt catalyst for total oxidation of trace toluene. Chin. J. Chem. Eng. 2014, 22, 882-887. [CrossRef]

36. Rui, Z.; Lu, Y.; Ji, H. Simulation of VOCs oxidation in a catalytic nanolith. RSC Adv. 2012, 3, 1103-1111. [CrossRef]

37. Chung, C.K.; Tsai, C.H.; Hsu, C.R.; Kuo, E.H.; Chen, Y.; Chung, I.C. Impurity and temperature enhanced growth behaviour of anodic aluminium oxide from AA5052 Al-Mg alloy using hybrid pulse anodization at room temperature. Corros. Sci. 2017, 125, 40-47. [CrossRef]

38. Chung, C.-K.; Liao, M.-W.; Lee, C.-T.; Chang, H.-C. Anodization of nanoporous alumina on impurity-induced hemisphere curved surface of aluminum at room temperature. Nanoscale Res. Lett. 2011, 6, 596. [CrossRef] [PubMed]

39. Zaraska, L.; Sulka, G.D.; Jaskuła, M. Anodic alumina membranes with defined pore diameters and thicknesses obtained by adjusting the anodizing duration and pore opening/widening time. J. Solid State Electrochem. 2011, 15, 2427-2436. [CrossRef]

40. Khodakov, A.Y.; Griboval-Constant, A.; Bechara, R.; Zholobenko, V.L. Pore size effects in Fischer Tropsch synthesis over cobalt-supported mesoporous silicas. J. Catal. 2002, 206, 230-241. [CrossRef]

41. Arnby, K.; Törncrona, A.; Andersson, B.; Skoglundh, M. Investigation of $\mathrm{Pt} / \gamma$-Al2O3 catalysts with locally high $\mathrm{Pt}$ concentrations for oxidation of CO at low temperatures. J. Catal. 2004, 221, 252-261. [CrossRef]

42. Rożeń, A. Simulation of start-up behaviour of a passive autocatalytic hydrogen recombiner. Nukleonika 2018, 63, 27-41. [CrossRef]

43. Du Preez, S.P.; Jones, D.R.; Warwick, M.E.A.; Falch, A.; Sekoai, P.T.; das Neves Quaresma, C.M.; Bessarabov, D.G.; Dunnill, C.W. Thermally stable Pt/Ti mesh catalyst for catalytic hydrogen combustion. Int. J. Hydrogen Energy 2020. [CrossRef]

44. Zhang, C.; Zhang, J.; Ma, J. Hydrogen catalytic combustion over a Pt/Ce0.6Zr0.4O2/MgAl2O4 mesoporous coating monolithic catalyst. Int. J. Hydrogen Energy 2012, 37, 12941-12946. [CrossRef]

45. Reinecke, E.-A.; Tragsdorf, I.M.; Gierling, K. Studies on innovative hydrogen recombiners as safety devices in the containments of light water reactors. Nucl. Eng. Des. 2004, 230, 49-59. [CrossRef]

46. Olsson, L.; Fridell, E. The Influence of Pt Oxide Formation and Pt Dispersion on the Reactions $\mathrm{NO} 2 \Leftrightarrow \mathrm{NO}+1 / 2 \mathrm{O} 2 \mathrm{over} \mathrm{Pt} / \mathrm{Al} 2 \mathrm{O} 3$ and $\mathrm{Pt} / \mathrm{BaO} / \mathrm{Al} 2 \mathrm{O} 3$. J. Catal. 2002, 210, 340-353. [CrossRef]

47. Hwang, C.-P.; Yeh, C.-T. Platinum-oxide species formed by oxidation of platinum crystallites supported on alumina. J. Mol. Catal. A Chem. 1996, 112, 295-302. [CrossRef]

48. Nagai, Y.; Hirabayashi, T.; Dohmae, K.; Takagi, N.; Minami, T.; Shinjoh, H.; Matsumoto, S. Sintering inhibition mechanism of platinum supported on ceria-based oxide and Pt-oxide-support interaction. J. Catal. 2006, 242, 103-109. [CrossRef]

49. Frank-Kamenetskii, D.A. Diffusion and Heat Exchange in Chemical Kinetics; Princeton University Press: Princeton, NJ, USA, 2015.

50. Kozhukhova, A.E.; Du Preez, S.P.; Bessarabov, D.G. Preparation of anodized aluminium oxide at high temperatures using low purity aluminium (Al6082). Surf. Coat. Tech. 2019, 378, 124970. [CrossRef]

51. Kozhukhova, A.E.; Du Preez, S.P.; Bessarabov, D.G. The effects of pore widening and calcination on anodized aluminum oxide prepared from Al6082. Surf. Coat. Tech. 2020, 383, 125234. [CrossRef] 
52. Rodi, W. Experience with two-layer models combining the k-epsilon model with a one-equation model near the wall. In 29th Aerospace Sciences Meeting; American Institute of Aeronautics and Astronautics: Reno, NV, USA, 1991.

53. Rinnemo, M.; Deutschmann, O.; Behrendt, F.; Kasemo, B. Experimental and numerical investigation of the catalytic ignition of mixtures of hydrogen and oxygen on platinum. Combust. Flame 1997, 111, 312-326. [CrossRef] 